\title{
Experiments for improving fabrication, recovery and surface-protection of $\mathrm{Cs}_{3} \mathrm{Sb}$ photocathode
}

\author{
Takayoshi Kimoto $^{\text {a, }}{ }^{*}$, Yoshihiro Arai ${ }^{b}$, Kuniak Nagayama ${ }^{c}$ \\ a Innovative Materials Engineering Laboratory, National Institute for Materials Science, \\ Tsukuba, Ibaraki 305-0047, Japan \\ ${ }^{\mathrm{b}}$ Terabase Inc., Okazaki, Aichi 444-8787, Japan \\ ${ }^{c}$ SOKENDAI, Graduate University for Advanced Studies, \\ Hayama, Kanagawa 240-0115, Japan \\ * Corresponding author: takaotomik@gmail.com
}

\begin{abstract}
We examined 1) the photocurrent from $\mathrm{Cs}_{3} \mathrm{Sb}$ photocathode as a function of anode voltage below $200 \mathrm{~V}, 2$ ) the relationship between the quantum efficiency of photoemission and the conditions for fabrication by the sandwich method, 3) recovery of the photoemission by additional Cs deposition, and 4) the effects of surface protection of $\mathrm{Cs}_{3} \mathrm{Sb}$ photocathodes by $\mathrm{WO}_{3}$ and $\mathrm{Cr}_{2} \mathrm{O}_{3}$ films in the passive state. The photocurrent had a maximum at approximately $68 \mathrm{~V}$ except when we increased the anode voltage extraordinarily slowly. $\mathrm{Cs}_{3} \mathrm{Sb}$ photocathodes were fabricated by increasing the temperature of sandwiched layers of $\mathrm{Sb}, \mathrm{Cs}$ and $\mathrm{Sb}$ deposited on the fine tips of eight cathodes at less than $-12^{\circ} \mathrm{C} . \mathrm{Cs}_{3} \mathrm{Sb}$ photocathodes having higher quantum efficiency were fabricated by smoothly increasing the temperature of the layers quickly after we deposited the second $\mathrm{Sb}$ layer. The photocurrent from the $\mathrm{Cs}_{3} \mathrm{Sb}$ photocathodes was significantly higher when Cs was deposited at temperatures of $50-70^{\circ} \mathrm{C}$. Deposition of a one- to three- atomic-layer $\mathrm{W}$ or $\mathrm{Cr}$ film extended the photoemission lifetime after the layers were oxidized to $\mathrm{WO}_{3}$ or $\mathrm{Cr}_{2} \mathrm{O}_{3}$ in the passive state due to oxidation. The $\mathrm{WO}_{3}$ or $\mathrm{Cr}_{2} \mathrm{O}_{3}$ in the passive state provided more surface protection as their thickness increased.
\end{abstract}

\section{Introduction}

Several photoemissive materials have extremely high quantum efficiency in the visible light region. For instance, the quantum efficiency of $\mathrm{Cs}_{3} \mathrm{Sb}$ is approximately 
$11 \%$ at a wavelength of $405 \mathrm{~nm}$, and $4.5 \%$ at $488 \mathrm{~nm}$ [1]. The quantum efficiency is generally defined as the ratio of the number of photoelectrons emitted via the photoelectric effect to the number of incident photons times 100. A cathode tip coated with $\mathrm{Cs}_{3} \mathrm{Sb}$ can emit photoelectrons with a current of approximately $18 \mathrm{~mA}$ and initial kinetic energies lower than $2.54 \mathrm{eV}$ if it is irradiated by a laser with a wavelength of 488 $\mathrm{nm}$ and an intensity of $1 \mathrm{~W}$. In comparison, the electron beam current in a transmission electron microscope (TEM), where the initial energy spread of the electron beam should be as small as possible, is usually approximately $50 \mu \mathrm{A}$ for a $\mathrm{LaB}_{6}$ thermal-type electron source, and 5-20 $\mu \mathrm{A}$ for a cold-field emission-type source [2]. Therefore, the electron current from laser-irradiated $\mathrm{Cs}_{3} \mathrm{Sb}$ could be much larger than those from the usual electron sources for TEMs. Because the quantum efficiencies of photocathodes of $\mathrm{K}_{3} \mathrm{Sb}$, $\mathrm{Rb}_{3} \mathrm{Sb}, \mathrm{Na}_{2} \mathrm{KSb}$, (Cs) $\mathrm{Na}_{2} \mathrm{KSb}, \mathrm{K}_{2} \mathrm{CsSb}, \mathrm{Cs}_{2} \mathrm{Te}, \mathrm{GaAs}(\mathrm{Cs})$, and so on are of the same order of magnitude as that of a $\mathrm{Cs}_{3} \mathrm{Sb}$ photocathode in the visible region [3], a cathode tip coated with one of these photoemissive materials could be an extremely high-intensity electron source for TEMs.

Because a higher-intensity electron source improves the performance of a TEM, a photocathode coated with one of these photoemissive materials could provide a better electron source for TEMs. In addition to extremely high intensity, the photocathode has the advantage that the interval of electron beam emission is easily controlled by controlling the laser irradiation. For example, a pulsed electron beam can be obtained by irradiation with a pulsed laser. A pulsed electron beam enables us to observe an organism in vivo because it does not cause fatal irradiation damage. We could deposit a $\mathrm{Cs}_{3} \mathrm{Sb}$ photocathode on a small selected area of a cathode tip by limiting the area of $\mathrm{Sb}$ and Cs deposition using a mask with a small hole [4]. Therefore, another advantage is the ability to easily change the size and shape of the electron beam by changing the shape of the photoemissive coating. In addition, our previous research found that the photocurrent from a $\mathrm{Cs}_{3} \mathrm{Sb}$ photocathode increased with increasing anode voltage from 0.4 to $7.0 \mathrm{kV}$ [4].

Despite the many advantages of the photocathode mentioned above, it has not been applied as an electron source for TEMs because many problems remain to be solved. The most important problem with the use of a photocathode coated with a photoemissive material such as $\mathrm{Cs}_{3} \mathrm{Sb}$ in TEMs is that the quantity of photoelectrons decreases rapidly with time in a vacuum chamber with an inadequate vacuum level. For a photocathode coated with $\mathrm{Cs}_{3} \mathrm{Sb}$, the decrease in photoelectron emission is thought to be caused by destruction of the crystal structure resulting from oxidation of the $\mathrm{Cs}_{3} \mathrm{Sb}$ photocathode and gradual loss of Cs [5]. It is also a serious problem that it is difficult to 
transfer the $\mathrm{Cs}_{3} \mathrm{Sb}$ photocathode from the vacuum chamber for deposition of $\mathrm{Sb}$ and $\mathrm{Cs}$ to a TEM without reducing its photoemission. The use of other photoemissive materials poses the same problem because these materials are extremely chemically active. They have been used in evacuated glass tubes such as photodiodes, photomultipliers, and imaging tubes, but they have extremely long lifetimes. The extremely long lifetime of a $\mathrm{Cs}_{3} \mathrm{Sb}$ photocathode in an evacuated glass tube, for example, seems to result from the presence of a small amount of residual Cs vapor in the tube, because this residual Cs vapor replaces any Cs that may be lost from the cathode surface and also attracts any oxygen that might poison the cathode [5]. On the other hand, when a $\mathrm{Cs}_{3} \mathrm{Sb}$ photocathode is used in a TEM or other vacuum chamber facility, the lifetime is thought to be much shorter than that in an evacuated glass tube. A short lifetime of a $\mathrm{Cs}_{3} \mathrm{Sb}$ photocathode in a vacuum chamber has been reported $[4,5]$, and efforts have also been made recently to increase the lifetimes of $\mathrm{Cs}_{3} \mathrm{Sb}$ and $\mathrm{K}-\mathrm{Cs}-\mathrm{Sb}$ photocathodes [6-9].

We found previously that the photocurrent from a $\mathrm{Cs}_{3} \mathrm{Sb}$ photocathode decreased with increasing anode voltage from 0.1 to $0.4 \mathrm{kV}$ and increased with increasing anode voltage from $0.4 \mathrm{kV}$ to $7 \mathrm{kV}$ [4]. We did not obtain data about the anode voltage dependence of the photocurrent for voltages below $0.1 \mathrm{kV}$ because the accuracy of the potentiometer was limited. The first objective of the present research is to determine the photocurrent from a $\mathrm{Cs}_{3} \mathrm{Sb}$ photocathode as a function of anode voltage for voltages of $0-0.2 \mathrm{kV}$.

The conventional method of fabricating a $\mathrm{Cs}_{3} \mathrm{Sb}$ photocathode is to deposit $\mathrm{Sb}$ and Cs alternatively on a cathode plate at approximately $130^{\circ} \mathrm{C}[3,5]$. However, this method is not suitable for our specially developed deposition equipment, which allows us to coat $\mathrm{Cs}_{3} \mathrm{Sb}$ on a small area of a fine cathode tip, because it is almost impossible for the equipment to switch quickly between deposition of $\mathrm{Sb}$ and $\mathrm{Cs}[4,10]$. Therefore, we developed a new fabrication method called the sandwich method [4]. In this method, we deposit $\mathrm{Sb}, \mathrm{Cs}$, and $\mathrm{Sb}$ in order on a cathode tip at a temperature below $-10^{\circ} \mathrm{C}$ and then increased the temperature of the cathode tip to $8-16^{\circ} \mathrm{C}$. However, the fabrication conditions required to obtain higher quantum efficiency of photoemission using the sandwich method have not been examined. The second objective of the present research is to find the sandwich method fabrication conditions that yield the highest quantum efficiency of photoemission.

We recently found that the photocurrent of a $\mathrm{Cs}_{3} \mathrm{Sb}$ photocathode was significantly increased by additional $\mathrm{Cs}$ deposition at elevated temperature [10]. Because the quantum efficiency of $\mathrm{Cs}_{3} \mathrm{Sb}$ photocathodes decreases with elapsed time, its recovery by additional $\mathrm{Cs}$ deposition is very important for the use of $\mathrm{Cs}_{3} \mathrm{Sb}$ photocathodes in TEMs. 
Because the photocurrent decreased rapidly with elapsed time after additional Cs deposition [4], we have to find the conditions required to decrease this reduction in order to make full use of additional Cs deposition. The third objective of the present research is to identify the best conditions for effective recovery of the photoemission from $\mathrm{Cs}_{3} \mathrm{Sb}$ photocathodes by additional Cs deposition.

We also found recently that a $\mathrm{WO}_{3}$ oxide film resulting from deposition of one- or two-atomic-layer-thick $\mathrm{W}$ film on the surface of $\mathrm{a} \mathrm{Cs}_{3} \mathrm{Sb}$ photocathode reduced the rate at which the photocurrent from a $\mathrm{Cs}_{3} \mathrm{Sb}$ photocathode decreased [10]. $\mathrm{The} \mathrm{Cr}_{2} \mathrm{O}_{3}$ oxide film resulting from deposition of 1.5-atomic-layer-thick $\mathrm{Cr}$ also extended the lifetime of a $\mathrm{Cs}_{3} \mathrm{Sb}$ photocathode [10]. We thought that both $\mathrm{WO}_{3}$ and $\mathrm{Cr}_{2} \mathrm{O}_{3}$ films in the passive state extended the lifetime of $\mathrm{Cs}_{3} \mathrm{Sb}$ photocathodes by protecting the surface from oxygen attack and gradual loss of $\mathrm{Cs}$ from $\mathrm{Cs}_{3} \mathrm{Sb}$. The fourth objective of the present research is to examine in detail the effect of $\mathrm{WO}_{3}$ and $\mathrm{Cr}_{2} \mathrm{O}_{3}$ films in the passive state on extension of the lifetime of $\mathrm{Cs}_{3} \mathrm{Sb}$ photocathodes.

\section{Experimental}

We previously developed vacuum deposition equipment for coating $\mathrm{Cs}_{3} \mathrm{Sb}$ photocathodes on a small area whose diameter is smaller than the cathode tip diameter of $0.2 \mathrm{~mm}$ [4]. To detect photoelectrons during additional Cs deposition, we then modified our original equipment by making a 2-mm-diameter hole in the center of the wedge prism used to reflect the laser inside the Faraday cup. Fig. 1 shows the modified deposition equipment for coating $\mathrm{Cs}_{3} \mathrm{Sb}$ photocathode on a small area of a fine cathode tip in a vacuum chamber. As shown in this figure, we could deposit additional Cs on a cathode tip while detecting photoelectrons with the Faraday cup. Because the details of our originally developed vacuum deposition equipment were described in our previous report [4], we provide only a brief description of it here. With the developed equipment, we can deposit $\mathrm{Sb}, \mathrm{Cs}$, and so forth on a cathode tip by heating a boat using an electron beam. $\mathrm{A} \mathrm{Cs}_{3} \mathrm{Sb}$ photocathode can be coated on a small area of the fine cathode tip by limiting the $\mathrm{Cs}$ and $\mathrm{Sb}$ deposition area using an aperture. After confirming the formation of $\mathrm{Cs}_{3} \mathrm{Sb}$ on a cathode tip by detection of photoelectrons using a Faraday cup, we set the cathode unit within a small vessel shield in an Ar gas atmosphere with a cover by using a wobblestick (or a type of 3-D manipulator). We can then transfer it from the vacuum deposition equipment to the specially designed or modified TEM without exposing it to air or oxygen.

Fig. 2 shows photographs of our modified TEM which enables us to introduce a photocathode from the small vessel shield in an Ar gas atmosphere into its electron gun. 
Fig. 2(a) shows the TEM in the normal condition, and Fig. 2(b) shows the TEM in the condition under which we introduce a photocathode into the electron gun. We introduce the small vessel including a cathode unit with a $\mathrm{Cs}_{3} \mathrm{Sb}$ photocathode from the area labeled "Entrance for Cathode." Because the cover for operation is filled with Ar gas after the vessel is introduced into the cover, we can remove the cathode unit from the vessel and set it in the electron gun using the glove without exposing it to air or oxygen. After we set the cathode unit in the electron gun, we remove the Ar gas from the cover for operation and lower the electron gun unit using the chain block. As shown in Fig. 2(a), we introduce a laser beam into the vacuum vessel of the TEM using an optical fiber and align the focused laser irradiation area and the cathode tip center using two XYZ-stages for an optical fiber and an endoscope, with a monitor for the endoscope.

We previously developed a new method, the so-called sandwich method fabricating $\mathrm{Cs}_{3} \mathrm{Sb}$ photocathodes that was suitable for our developed deposition equipment $[4,10]$. Fig. 3 shows a schematic diagram of this method. After baking a Ni cathode tip for $2 \mathrm{~h}$ at $200^{\circ} \mathrm{C}$, we deposited 8 -nm-thick $\mathrm{Cr}$ on the surface of the cathode tip, because $\mathrm{Sb}$ reacts chemically with $\mathrm{Ni}$ [3]. After again baking the cathode tip for $2 \mathrm{~h}$ at $200^{\circ} \mathrm{C}$, we deposited 8-nm-thick Sb, 93-nm-thick $\mathrm{Cr}$ and 4-nm-thick $\mathrm{Sb}$ at -18 to $-12^{\circ} \mathrm{C}$, as shown in Fig. 3(a). After the second $\mathrm{Sb}$ deposition, we increased the temperature of the cathode tip from -18 to $-12^{\circ} \mathrm{C}$ to $6-40^{\circ} \mathrm{C}$ to form $\mathrm{Cs}_{3} \mathrm{Sb}$. Details of the evaporation of $\mathrm{Sb}, \mathrm{Cs}$, and so on were described in our previous report [4].

Table 1 summarizes the experimental conditions. We performed eight experiments, mainly to examine in detail the surface protection provided by $\mathrm{WO}_{3}$ and $\mathrm{Cr}_{2} \mathrm{O}_{3}$ thin films in the passive state on $\mathrm{Cs}_{3} \mathrm{Sb}$ photocathodes. In experiments I and II, we examined mainly the effects of a $\mathrm{WO}_{3}$ film, and we examined those of a $\mathrm{Cr}_{2} \mathrm{O}_{3}$ film in experiments III-VIII. The deposited thicknesses of the $\mathrm{W}$ film were one or three atomic layers, and those of the $\mathrm{Cr}$ films were one to three atomic layers. Note that the effect of baking in experiment I was larger than that in the other experiments despite a much shorter baking time because of the slightly higher baking temperature. The upper chamber shown in Fig. 1 was evacuated by a cryopump or turbo molecular pump (TMP) in experiments II, V, and VII, but it was evacuated only by the TMP in I, III, IV, VI, and VIII. In all the experiments, the effects of additional Cs deposition on the photoemission were examined before or during the lifetime test of photoemission from the $\mathrm{Cs}_{3} \mathrm{Sb}$ photocathode.

\section{Results and Discussion}

3.1 Photocurrent as a function of anode voltage below $200 \mathrm{~V}$ 
In our previous research we extracted photoelectrons from $\mathrm{Cs}_{3} \mathrm{Sb}$ using an extracting voltage or anode voltage of $1 \mathrm{kV}[4,10]$, but in the present research, we extracted photoelectrons using an anode voltage of $0.1 \mathrm{kV}$.

We previously examined the effect of the anode voltage on the photocurrent from a $\mathrm{Cs}_{3} \mathrm{Sb}$ photocathode [4]. We found that the normalized photocurrent decreased from 1.13 to 0.4 with increasing voltage from 0.1 to $0.4 \mathrm{kV}$, but increased from 0.4 to 1.93 with increasing voltage from 0.4 to $7 \mathrm{kV}$. Because the photocurrent at $0.1 \mathrm{kV}$ was 1.13 times that at $1 \mathrm{kV}$, the photocurrent in the present research is almost the same as that in our previous research obtained at $1 \mathrm{kV}[4,10]$. As the photocurrent from a $\mathrm{Cs}_{3} \mathrm{Sb}$ photocathode as a function of anode voltage has not been reported at anode voltages below $0.1 \mathrm{kV}(100 \mathrm{~V})$ [4], we examined precisely the photocurrent at anode voltages below about $200 \mathrm{~V}$ in the present research.

Fig. 4 shows the photocurrent as a function of anode voltage below $196 \mathrm{~V}$. The photocurrent was normalized so that it was 1.0 at $9 \mathrm{~V}$. The data were obtained by increasing the anode voltage from 9 to $196 \mathrm{~V}$ for $35 \mathrm{~min}$ in increments of approximately $10 \mathrm{~V}$. The normalized photocurrent increased gradually from 1.0 to 1.24 with increasing voltage from 9 to $39 \mathrm{~V}$ and increased rapidly from 1.24 to 3.27 with increasing voltage from 39 to $68 \mathrm{~V}$. The normalized photocurrent then decreased gradually from 3.27 to 2.57 with increasing voltage from 68 to $196 \mathrm{~V}$. The decrease in photocurrent as the anode voltage increased from 68 to $196 \mathrm{~V}$ corresponds well qualitatively to our previous report, in which the normalized photocurrent decreased from 1.130 to 0.724 with increasing voltage from 100 to $200 \mathrm{~V}$ [4]. In the present research, the ratio of photocurrent at $98 \mathrm{~V}$ to that at $196 \mathrm{~V}$ was 0.839 . However, in our previous research, the ratio of the photocurrent at $100 \mathrm{~V}$ to that at $200 \mathrm{~V}$ was 0.641 [4]. This quantitative discrepancy could be caused by the lower accuracy of the voltage in our previous research, because the minimum scale of the voltage in the potentiometer was $10 \mathrm{~V}$ in the present research but $200 \mathrm{~V}$ in our previous experiment [4].

Fig. 5 shows the photocurrent as a function of anode voltage below $196 \mathrm{~V}$, where the anode voltage was increased extremely slowly. The photocurrent was normalized so that it was 1.0 at $9 \mathrm{~V}$, and the data were obtained by increasing the anode voltage from 3 to $196 \mathrm{~V}$ for $61.5 \mathrm{~min}$ in increments of approximately $5 \mathrm{~V}$. The normalized photocurrent increased rapidly from 0.00 to 1.76 with increasing voltage from 0 to $14 \mathrm{~V}$, but decreased from 1.76 to 1.24 with increasing voltage from 14 to $19 \mathrm{~V}$. The normalized photocurrent decreased very slowly from 1.33 to 0.810 with increasing voltage from 24 to $93 \mathrm{~V}$, but it increased abruptly from 0.905 to 5.52 from 98 to $102.5 \mathrm{~V}$. The normalized photocurrent then decreased slowly from 5.52 to 4.86 with increasing 
anode voltage from 102.5 to $196 \mathrm{~V}$.

The large difference between Figs. 4 and 5 suggests that the photocurrent was significantly affected by the speed at which the anode voltage was increased below 200 $\mathrm{V}$. This phenomenon is physically very interesting, and it might give us important information for understanding photoelectric emission. We do not explain this phenomenon theoretically at present. Because we usually increased the anode voltage from 0 to $100 \mathrm{~V}$ within $10 \mathrm{~s}$, the effect of this phenomenon could be ignored in measuring the photocurrent in the present research.

\section{2 Fabrication of $\mathrm{Cs}_{3} \mathrm{Sb}$ photocathode with "sandwich method"}

We tried to identify better fabrication conditions using the sandwich method that would yield more photoelectrons. The results of experimental fabrication of $\mathrm{Cs}_{3} \mathrm{Sb}$ photocathodes are shown in Table 2. We show the quantum efficiency for the first-detected photocurrent, the first detection time $t$ after the second Sb deposition (in parentheses), the cathode temperature change between the second $\mathrm{Sb}$ deposition and the first photocurrent detection time $t$, and the vacuum level at the cathode tip. There have been several reports on the quantum efficiency spectra of semitransparent $\mathrm{Cs}_{3} \mathrm{Sb}$ photocathodes fabricated by exposing $\mathrm{Cs}$ to $\mathrm{Sb}$ deposited on a glass plate at a temperature of $130-150^{\circ} \mathrm{C}$ in an evacuated glass tube $[1,11,12]$. The quantum efficiencies of the $\mathrm{Cs}_{3} \mathrm{Sb}$ photocathodes at $405 \mathrm{~nm}$ were $11.1 \%$ [1], 6.8\% [11], and $18.6 \%$ [12]. The quantum efficiencies of the $\mathrm{Cs}_{3} \mathrm{Sb}$ photocathodes in experiments II, III, and VI are comparable to these values. As shown in table 2, however, the quantum efficiency varied significantly among the eight experiments.

Fig. 6 shows the temperature of the cathode tips as a function of elapsed time from the second $\mathrm{Sb}$ deposition to the first detection of photocurrent in experiments I, IV, $\mathrm{V}$, and VIII, the first-detected quantum efficiencies of which were smaller than $1 \%$. Fig. 7 shows the same graph as Fig. 6 for experiments II, III, IV, and VII, the first-detected quantum efficiencies of which were larger than $1 \%$. In these figures, we show the first-detected quantum efficiencies in each case. When we compare Figs. 6 and 7, large difference between them becomes apparent. The temperature increased in steps in the experiments with quantum efficiencies smaller than $1 \%$ (II, III, IV, and VIII), as shown in Fig. 6, but it increased smoothly in the experiments with quantum efficiencies larger than $1 \%$ (II, III, IV, and VIII), as shown in Fig. 7. This feature implies that a smooth increase in the cathode temperature after the second $\mathrm{Sb}$ deposition is necessary for obtaining a higher quantum efficiency.

In experiment $\mathrm{IV}$, the extremely small quantum efficiency of $0.0385 \%$ could 
be caused partly by the low cathode temperature of $6^{\circ} \mathrm{C}$ when the photocurrent was first detected, because the cathode temperature increased almost smoothly (Fig. 6). On the other hand, the quantum efficiency of $2.58 \%$ in experiment III was not small despite the low cathode temperature of $7^{\circ} \mathrm{C}$ when the photocurrent was first detected (Fig. 7). The great difference in quantum efficiency between experiments IV and III does not seem to be explained only by the difference in cathode temperature and the smooth increase in cathode temperature. However, the time at which the cathode temperature began to increase after the second $\mathrm{Sb}$ deposition and the initial speed of the temperature increase differed significantly between experiments IV and III. In experiment IV, the cathode temperature was $-15^{\circ} \mathrm{C}$ at 0,1 , and $3 \mathrm{~min}$, and $-6^{\circ} \mathrm{C}$ at $8 \mathrm{~min}$. In experiment III, the cathode temperature was $-16^{\circ} \mathrm{C}$ at 0 and $1 \mathrm{~min},-12^{\circ} \mathrm{C}$ at $3 \mathrm{~min},-5^{\circ} \mathrm{C}$ at $6 \mathrm{~min}$, $-2^{\circ} \mathrm{C}$ at $8 \mathrm{~min}$. We expect, therefore, that the difference in the temperature increase, especially from 0 to $3 \mathrm{~min}$, could be the main cause of the large difference in quantum efficiency between experiments IV and III.

This expectation regarding the results of experiments IV and III is roughly consistent with the other results. As shown in Fig. 6, the temperature increase from 0 to 3 min was $5^{\circ} \mathrm{C}$ in experiment VIII, where the quantum efficiency was $0.510 \%$, and it was $0^{\circ} \mathrm{C}$ in experiment $\mathrm{I}$, where the quantum efficiency was $0.319 \%$. We cannot comment on experiment $\mathrm{V}$ because we had no data on the cathode temperature at $3 \mathrm{~min}$. As shown in Fig. 7, the temperature increase from 0 to 3 min was $1^{\circ} \mathrm{C}$ in experiment IV, where the quantum efficiency was $9.17 \% ; 2^{\circ} \mathrm{C}$ in experiment II, where the quantum efficiency was $4.95 \%$; and $0^{\circ} \mathrm{C}$ in experiment VII, where the quantum efficiency was $1.06 \%$. The apparent anomaly between experiments II and IV could be explained by two facts. First, the cathode temperature at which the photocurrent was first detected in experiment II was $12^{\circ} \mathrm{C}$ lower than that in experiment IV. In addition, the secondary cathode temperature at $0 \mathrm{~min}$ in experiment II was $6^{\circ} \mathrm{C}$ lower than that in experiment IV.

\subsection{Recovery of photoemission from $\mathrm{Cs}_{3} \mathrm{Sb}$ photocathode by additional Cs deposition}

We found previously that an additional $\mathrm{Cs}$ deposition on a $\mathrm{Cs}_{3} \mathrm{Sb}$ photocathode at elevated temperature increased the photoemission of the $\mathrm{Cs}_{3} \mathrm{Sb}$ photocathode [10]. In the present research we tried to find the optimal experimental condition for recovery of the photocurrent. Our previous experimental results suggested that the optimal cathode temperature for additional Cs deposition in our evaporation-boat heater would be between approximately $50^{\circ} \mathrm{C}$ and $80^{\circ} \mathrm{C}$ [10]. Our previous results also suggested that increasing the cathode temperature during Cs deposition would be favorable for 
increasing the photocurrent. In contrast, it was suggested that decreasing the cathode temperature during $\mathrm{Cs}$ deposition would not be favorable for increasing the photocurrent.

Table 3 summarizes the results regarding the recovery of photoemission from $\mathrm{Cs}_{3} \mathrm{Sb}$ photocathodes by additional $\mathrm{Cs}$ deposition. On the left side of this table, we show the quantum efficiency $Q_{\mathrm{s}}$ at the time that additional Cs deposition began, the maximum quantum efficiency $Q_{\max }$ during additional Cs deposition, the ratio $Q_{\max } / Q_{s}$, the change in cathode temperature during additional Cs deposition, and the period $\Delta t$ (min) of Cs deposition. On the right side, we show the quantum efficiency $Q_{t}$ at time $t$, the time $t_{\mathrm{e}}$ (min) at which photocurrent detection ended after Cs deposition ended (in parentheses), the ratio $Q_{t} / Q_{\max }$, and the decrease in temperature from $t=0$ to $t=t_{\mathrm{e}}$. The quantum efficiencies were increased significantly by additional Cs deposition in all the experiments. However, the ratio $Q_{\max } / Q_{\mathrm{s}}$ differed greatly among the experiments. The maximum value was 426.1 in experiment VII, and the minimum value was 2.6 in experiment VIII. Following the suggestion from our previous results, we tried to realize temperatures that were between 50 and $67^{\circ} \mathrm{C}$ for the $\mathrm{Cs}_{3} \mathrm{Sb}$ photocathode and that increased gradually or remained constant during additional Cs deposition, as shown in table 3. From the results shown in table 3, the cathode temperature of $50-70^{\circ} \mathrm{C}$ during additional Cs deposition is favorable for effectively increasing the photoemission. The ratio $Q_{t} / Q_{\max }$ is relatively large for experiments II, V, and VII. This means that the reduction in photocurrent after Cs deposition was small in these experiments.

We obtained graphs showing the normalized photocurrent and cathode temperature as a function of the elapsed time during additional Cs deposition for all eight experiments. Figs. 8-10 show the graphs for experiments I, V, and VII, respectively, as typical examples. In these figures, the photocurrent is normalized to be unity at $t=0 \mathrm{~min}$, and the period of additional Cs deposition is indicated by arrows. In most cases, the photocurrent increased with increasing time of additional Cs deposition, and it reached a maximum near the end of Cs deposition.

As shown in Fig. 8, the normalized photocurrent increased steeply from 1 to approximately 173 between 25 and $41 \mathrm{~min}$. The cathode temperature was $60-61^{\circ} \mathrm{C}$ during Cs deposition. After $41 \mathrm{~min}$, the photocurrent increased slowly, and the normalized photocurrent had a maximum of 181.7 at $53 \mathrm{~min}$, which was 8 min before Cs deposition ended. The quantum efficiency corresponding to the maximum photocurrent at 53 min was $2.06 \%$, which is not the maximum value for the $\mathrm{Cs}_{3} \mathrm{Sb}$ photocathodes. We think that photocurrent stopped increasing at approximately $45 \mathrm{~min}$ because of a decrease in the Cs evaporation rate due to a decrease in the amount of 
evaporative material for $\mathrm{Cs}\left(\mathrm{CsCrO}_{4}\right)$ in the boat. The normalized photocurrent decreased rapidly from 179.8 to 98.4 between 61 and 110 min, as shown in Fig. 8. A rapid decrease in photocurrent after additional Cs deposition was observed in most of the experiments. A rapid decrease in photocurrent with time also occurs just after fabrication of $\mathrm{Cs}_{3} \mathrm{Sb}$ photocathodes $[4,10]$. As shown in table $3, Q_{t} / Q_{\max }$ is relatively large in experiments II, V, and VII. This means that the photocurrent did not decrease rapidly after additional Cs deposition in these experiments. Because $Q_{\max } / Q_{\mathrm{s}}$ was only 2.6 during additional $\mathrm{Cs}$ deposition in experiment II, we think that this small increase could be the cause of the small reduction after additional Cs deposition. Therefore, we should examine in detail the results of experiments V and VII to find the cause of the small reduction in photocurrent after additional Cs deposition ended.

As shown in Fig. 9, the normalized photocurrent increased from 1.0 to 13.4 between 35 and 65 min during additional $\mathrm{Cs}$ deposition in experiment V. The cathode temperature increased rapidly from 52 to $58^{\circ} \mathrm{C}$ between 35 and $45 \mathrm{~min}$, but it increased slowly from 58 to $62^{\circ} \mathrm{C}$ between 45 and 65 min. After Cs deposition, we decreased the cathode temperature rapidly from 61 to $41^{\circ} \mathrm{C}$ between 65 and $75 \mathrm{~min}$, and then we decreased it gradually from 41 to $39^{\circ} \mathrm{C}$ between 75 and $110 \mathrm{~min}$. The normalized photocurrent showed a corresponding decrease from 13.4 to 10.4 between 75 and 110 min. The reduction in photocurrent after additional $\mathrm{Cs}$ deposition in experiment $\mathrm{V}$ was smaller than that in the other experiments except for experiment VII. The fact that the temperature was maintained around $40^{\circ} \mathrm{C}$ between 75 and $110 \mathrm{~min}$ is likely the cause of the smaller reduction in photocurrent after additional Cs deposition in experiment V. This is similar to the result in our previous research [10].

As shown in Fig. 10, the normalized photocurrent increased from 1.0 to 426.1 between 35 and 75 min during additional Cs deposition in experiment VII. The cathode temperature increased very slowly from 63 to $67^{\circ} \mathrm{C}$ between 35 and $75 \mathrm{~min}$. Because the increase in photocurrent after additional Cs deposition was very large in experiment VII, keeping the temperature around $65^{\circ} \mathrm{C}$ would be preferable during additional $\mathrm{Cs}$ deposition. After $\mathrm{Cs}$ deposition, we decreased the cathode temperature gradually from 67 to $44^{\circ} \mathrm{C}$ between 75 and $110 \mathrm{~min}$, and the normalized photocurrent showed a corresponding gradual decrease from 426.1 to 383.5 . The rate at which the photocurrent decreased after Cs deposition was slowest in experiment VII. We think that the gradual decrease in photocurrent after additional Cs deposition in experiment VII was caused by the gradual decrease in cathode temperature.

In summary, additional $\mathrm{Cs}$ deposition resulted in significant recovery of the photocurrent from a $\mathrm{Cs}_{3} \mathrm{Sb}$ photocathode if the cathode temperature was maintained 
between approximately $50^{\circ} \mathrm{C}$ and approximately $70^{\circ} \mathrm{C}$ under the present experimental conditions. The rapid reduction in photocurrent after additional Cs deposition was suppressed most effectively by gradually decreasing the cathode temperature to approximately $40-45^{\circ} \mathrm{C}$. Therefore, we think that the installation of a device for evacuation of $\mathrm{Cs}$ within TEMs would be very helpful to realize the use of $\mathrm{Cs}_{3} \mathrm{Sb}$ photocathodes for TEMs, because we could recover the photoemission from the cathodes almost perfectly by using the evaporation device at intervals. Because a sufficiently high vacuum level should be maintained in the chamber containing the $\mathrm{Cs}_{3} \mathrm{Sb}$ photocathode, we should remove the evaporation device from the chamber after evaporation without decreasing vacuum level of the TEM chamber at all and isolate it from the TEM chamber using an isolation valve.

\subsection{Surface protection of $\mathrm{Cs}_{3} \mathrm{Sb}$ photocathode by $\mathrm{WO}_{3}$ or $\mathrm{Cr}_{2} \mathrm{O}_{3}$ film in passive state}

We performed lifetime tests in the eight independent experiments listed in table 1 (I-VIII), and we examined the surface protection effects of $\mathrm{WO}_{3}$ or $\mathrm{Cr}_{2} \mathrm{O}_{3}$ during these tests. We obtained eight graphs showing the common logarithm of the normalized photocurrent as a function of elapsed time for each experiment. We show the graphs for experiments II and VIII as typical examples in order to explain in detail the effects of $\mathrm{WO}_{3}$ or $\mathrm{Cr}_{2} \mathrm{O}_{3}$.

Figs. 11 and 12 show the common logarithm of the normalized photocurrent as a function of the elapsed time in experiment II, in which we examined the surface protection effect of $\mathrm{WO}_{3}$ in the passive state. Fig. 11 shows the result between 0 and 190 h, and Fig. 12 shows that between 190 and $357 \mathrm{~h}$. We found previously that the common logarithm of the photocurrent decreased linearly under the same physical conditions [4, 10], so we used the common logarithmic scale instead of the linear scale in these graphs. As shown in table 1, we performed additional Cs deposition $18 \mathrm{~h}$ before the lifetime test began. During the lifetime test, the photocurrent was measured after approximately $10 \mathrm{~s}$ of laser irradiation. As shown in Fig. 11, we deposited three atomic layers (a total of $0.95 \mathrm{~nm}$ in thickness) of $\mathrm{W}$ at $t=8-9 \mathrm{~h}$ during the lifetime test in experiment II. Before W deposition, the common logarithm of the photocurrent decreased at a rate of approximately $-0.00842 / \mathrm{h}$ starting at $0 \mathrm{~h}$, but it decreased rapidly at a rate of approximately $-0.679 / \mathrm{h}$ during $\mathrm{W}$ deposition. Deposition of the $\mathrm{W}$ film decreased the photocurrent by a factor of approximately 0.41 . It took approximately $63 \mathrm{~min}$ to deposit three atomic layers (a total of $0.95 \mathrm{~nm}$ in thickness) of $\mathrm{W}$, and the vacuum level during deposition of the $\mathrm{W}$ film was reduced to $1.8-3.0110^{-7} \mathrm{~Pa}$. This reduction in vacuum level could be the main cause of the rapid decrease in photocurrent during $\mathrm{W}$ deposition. 
Another cause could be absorption of photoelectrons by the $\mathrm{W}$ film. After deposition of the $\mathrm{W}$ film, the common logarithm of the photocurrent decreased gradually at a rate of approximately $-0.00162 / \mathrm{h}$ until $124 \mathrm{~h}$. We think that $\mathrm{WO}_{3}$ was formed during the period of 63 min during which the $\mathrm{W}$ film was deposited because the vacuum level was low enough for the $\mathrm{W}$ film to be oxidized. We think that the $\mathrm{WO}_{3}$ in the passive state that formed during deposition of the $\mathrm{W}$ film caused this extremely slow decrease in the common logarithm of the photocurrent from 9 to $124 \mathrm{~h}$ by protecting the surface of the $\mathrm{Cs}_{3} \mathrm{Sb}$ photocathode.

We irradiated the cathode tip continuously with a $405 \mathrm{~nm}$ laser between 125 and $245 \mathrm{~h}$. The laser intensity at the surface of the cathode tip was $0.0016 \mathrm{~W} / \mathrm{cm}^{2}$ from 125 to $149 \mathrm{~h}$ and $0.0017 \mathrm{~W} / \mathrm{cm}^{2}$ from 149 to $245 \mathrm{~h}$ (Figs. 11 and 12). Note that we extracted photoelectrons continuously from 145 to $179 \mathrm{~h}$. The common logarithm of the photocurrent decreased at a rate of $-0.00958 / \mathrm{h}$ between 125 and $149 \mathrm{~h}$, at a rate of $0.00901 / \mathrm{h}$ between 149 and $179 \mathrm{~h}$, and at a rate of $-0.00452 / \mathrm{h}$ between 179 and $245 \mathrm{~h}$. Therefore, the rate at which the photocurrent decreased was enhanced by continuous laser irradiation. An enhanced rate of decrease under continuous laser irradiation was also observed in our previous research [10]. We think that this phenomenon could be caused by photo-oxidation. Light irradiation is known to promote chemical reactions in a material because absorption of light increases the energy of electrons in the material. If oxidation of the $\mathrm{Cs}_{3} \mathrm{Sb}$ photocathode is enhanced by laser irradiation, the quantum efficiency of the photocathode could decrease more rapidly because oxidation poisons the photocathode. We think that the rate between 179 and $245 \mathrm{~h},-0.00452 / \mathrm{h}$, was somewhat smaller than that between 125 and $149 \mathrm{~h},-0.00958 / \mathrm{h}$, because the $\mathrm{WO}_{3}$ was strengthened by photo-oxidation during continuous laser irradiation.

When we reduced the vacuum level from $1.1 \times 10^{-7}$ to $2.1 \times 10^{-7} \mathrm{~Pa}$ at 245 $\mathrm{h}$, the common logarithm of the photocurrent decreased rapidly at a rate of $-0.309 / \mathrm{h}$ between 245 and $246 \mathrm{~h}$. However, the common logarithm of the photocurrent decreased very slowly (at a rate of $-0.00177 / \mathrm{h}$ ) between 250 and $271 \mathrm{~h}$. The vacuum level was changed by changing the evacuation pump for the upper chamber from the cryopump to the TMP. We think that the much slower decrease between 250 and $271 \mathrm{~h}$ was caused by re-strengthening of the $\mathrm{WO}_{3}$ in the passive state due to oxidization during the period of lower vacuum level between 245 and $246 \mathrm{~h}$, which provided better protection for the surface of the $\mathrm{Cs}_{3} \mathrm{Sb}$ photocathode. We gradually increased the temperature of the upper chamber containing the cathode tip between 269 and $275 \mathrm{~h}$ from 6 to $26^{\circ} \mathrm{C}$. In conjunction with this temperature increase, the common logarithm of the photocurrent decreased somewhat more steeply, at a rate of $-0.0198 / \mathrm{h}$, between 271 and $275 \mathrm{~h}$. We 
think that the increase in the temperature of the upper chamber from 6 to $26^{\circ} \mathrm{C}$ caused the more rapid decrease in the photocurrent by increasing the vapor pressure of $\mathrm{H}_{2} \mathrm{O}$ in the upper chamber, which enhanced the oxidation of the $\mathrm{Cs}_{3} \mathrm{Sb}$ photocathode. The common logarithm of the photocurrent decreased very slowly (at a rate of $-0.00352 / \mathrm{h}$ ) between 275 and $293 \mathrm{~h}$.

We again applied continuous laser irradiation beginning at $293 \mathrm{~h}$. The common logarithm of the photocurrent decreased rapidly (at a rate of $-0.103 / \mathrm{h}$ ) between 293 and $295 \mathrm{~h}$, but it became almost constant between 295 and $297 \mathrm{~h}$, probably because of re-strengthening of $\mathrm{WO}_{3}$ in the passive state by photo-oxidation. We changed the vacuum level from $2.1 \times 10^{-7}$ to $1.1 \times 10^{-7} \mathrm{~Pa}$ at $297 \mathrm{~h}$; the common logarithm of the photocurrent then increased at a rate of $+0.00352 / \mathrm{h}$ between 297 and $313 \mathrm{~h}$. After we increased the laser intensity from 0.0016 to $0.0037 \mathrm{~W} / \mathrm{cm}^{2}$ at $313 \mathrm{~h}$, the common logarithm of the photocurrent decreased at a rate of $-0.0506 / \mathrm{h}$ until $314 \mathrm{~h}$, and it decreased at a rate of $-0.00454 / \mathrm{h}$ between 314 and $336 \mathrm{~h}$. After we reduced the vacuum level from $1.1 \times 10^{-7}$ to $2.1 \times 10^{-7} \mathrm{~Pa}$ at $336 \mathrm{~h}$, the common logarithm of the photocurrent decreased at a rate of $-0.0221 / \mathrm{h}$ between 336 and $343 \mathrm{~h}$ under a laser intensity of $0.0016 \mathrm{~W} / \mathrm{cm}^{2}$. It decreased at a rate of $-0.0377 / \mathrm{h}$ between 343 and $357 \mathrm{~h}$ under a laser intensity of $0.0037 \mathrm{~W} / \mathrm{cm}^{2}$.

The analysis of Figs. 11 and 12 indicated that deposition of the three-atomic-layer (0.95-nm-thick) W film greatly extended the lifetime of the photoemission of the $\mathrm{Cs}_{3} \mathrm{Sb}$ photocathode after the $\mathrm{W}$ film was oxidized to $\mathrm{WO}_{3}$ in the passive state. The $\mathrm{WO}_{3}$ could provide more protection for the $\mathrm{Cs}_{3} \mathrm{Sb}$ photocathode surface after the vacuum level was reduced. The protective effect of $\mathrm{WO}_{3}$ could also be strengthened by photo-oxidation during continuous laser irradiation.

Figs. 13 and 14 show the common logarithm of the normalized photocurrent as a function of the elapsed time in experiment VII, in which we examined the surface protection effect of $\mathrm{Cr}_{2} \mathrm{O}_{3}$ in the passive state. Fig. 13 shows the result between 0 and 250 h, and Fig. 14 shows that between 250 and 455 h. After the common logarithm of the normalized photocurrent decreased rapidly between 0 and $5 \mathrm{~h}$, it decreased at a rate of $-0.0149 / \mathrm{h}$ between 5 and $23 \mathrm{~h}$. We deposited three atomic layers (a total of $0.87 \mathrm{~nm}$ in thickness) of $\mathrm{Cr}$ at approximately $23.5 \mathrm{~h}$. As shown in Fig. 13, deposition of the $\mathrm{Cr}$ film decreased the photocurrent by a factor of approximately 0.34. It took approximately $5 \mathrm{~min}$ to deposit three atomic layers of $\mathrm{Cr}$, and the vacuum level during deposition of the $\mathrm{Cr}$ film was reduced to $1.6-2.1 \times 10^{-7} \mathrm{~Pa}$. We think that both the reduction of the vacuum level during deposition of the $\mathrm{Cr}$ film and the absorption of photoelectrons by the $\mathrm{Cr}$ film were the main causes for the rapid decrease in 
photocurrent during $\mathrm{Cr}$ deposition. The common logarithm of the photocurrent decreased gradually at a rate of approximately $-0.00795 / \mathrm{h}$ between 29 and $42 \mathrm{~h}$. We think that the $\mathrm{Cr}_{2} \mathrm{O}_{3}$ in the passive state, which was not so strong to protect the surface of the $\mathrm{Cs}_{3} \mathrm{Sb}$ photocathode, was formed during the period of 5 minutes for the deposition of $\mathrm{Cr}$ film because the vacuum level was low for the $\mathrm{Cr}$ film to be oxidized. After we reduced the vacuum level from $1.1 \times 10^{-7}$ to $2.2 \times 10^{-7} \mathrm{~Pa}$ at $42 \mathrm{~h}$, the common logarithm of the photocurrent decreased rapidly (at a rate of $-0.306 / \mathrm{h}$ ) between 42 and $45 \mathrm{~h}$.

After this rapid decrease in the common logarithm of the photocurrent, the rate of decrease became increasingly smaller. The common logarithm of the photocurrent decreased very slowly (at a rate of $-0.00152 / \mathrm{h}$ ) between 186 and $214 \mathrm{~h}$. We think that the surface protection by $\mathrm{Cr}_{2} \mathrm{O}_{3}$ in the passive state was strengthened during the long period from 42 to $186 \mathrm{~h}$. The rate of decrease, $-0.00152 / \mathrm{h}$, for $\mathrm{Cr}_{2} \mathrm{O}_{3}$ was smaller than that between 275 and $293 \mathrm{~h}$ for $\mathrm{WO}_{3},-0.00352 / \mathrm{h}$. This result suggests that the maximum surface protection provided by $\mathrm{Cr}_{2} \mathrm{O}_{3}$ in the passive state formed from three atomic layers of $\mathrm{Cr}$ could be stronger than that provided by $\mathrm{WO}_{3}$ in the passive state formed from three atomic layers of W.

We changed the vacuum level from $2.2 \times 10^{-7}$ to $1.0 \times 10^{-7} \mathrm{~Pa}$ at $211 \mathrm{~h}$, and we deposited additional Cs between 214 and $215 \mathrm{~h}$. The photocurrent increased by 426.1 times after this additional Cs deposition. This is the first observation of effective recovery of the photoemission of a $\mathrm{Cs}_{3} \mathrm{Sb}$ photocathode by additional $\mathrm{Cs}$ deposition even when the cathode's surface was coated with $\mathrm{Cr}_{2} \mathrm{O}_{3}$ in the passive state. This could imply that $\mathrm{Cs}$ atoms penetrated the protective $\mathrm{Cr}_{2} \mathrm{O}_{3}$ in the passive state. The common logarithm of the photocurrent decreased at a rate of $-0.00740 / \mathrm{h}$ between 216 and $238 \mathrm{~h}$. Because the rate of $-0.00740 / \mathrm{h}$ was larger than that between 186 and $211 \mathrm{~h},-0.00152 / \mathrm{h}$, when the vacuum level was $2.2 \times 10^{-7} \mathrm{~Pa}$, we think that the surface protection by $\mathrm{Cr}_{2} \mathrm{O}_{3}$ in the passive state was seriously weakened by additional Cs deposition. As shown in Figs. 13 and 14, the rate of decrease of the common logarithm of the photocurrent became slow between 216 and $309 \mathrm{~h}$. It decreased at a rate of $-0.00163 / \mathrm{h}$ between 282 and $309 \mathrm{~h}$.

We again reduced the vacuum level from $1.0 \times 10^{-7}$ to $2.0 \times 10^{-7} \mathrm{~Pa}$ at 309 $\mathrm{h}$. The common logarithm of the photocurrent decreased rapidly (at a rate of $-0.155 / \mathrm{h}$ ) between 309 and $314 \mathrm{~h}$. This result clearly confirmed that the surface protection effect of $\mathrm{Cr}_{2} \mathrm{O}_{3}$ in the passive state was almost eliminated by additional Cs deposition, because the rate of $-0.155 / \mathrm{h}$ was almost equivalent to that between 42 and $45 \mathrm{~h},-0.306 / \mathrm{h}$. This implies that the crystal structure of $\mathrm{Cr}_{2} \mathrm{O}_{3}$ in the passive state was completely destroyed 
by additional Cs deposition. After the common logarithm of the photocurrent decreased rapidly between 307 and $314 \mathrm{~h}$, it very quickly became almost zero. The common logarithm of the photocurrent decreased at a rate of $-0.000832 / \mathrm{h}$ between 316 and $356 \mathrm{~h}$. This implies that $\mathrm{Cr}_{2} \mathrm{O}_{3}$ in the passive state was formed again within a very short time. Because the rate of $-0.000832 / \mathrm{h}$ is much smaller than that between 186 and $211 \mathrm{~h}$, $0.00152 / \mathrm{h}$, the $\mathrm{Cr}_{2} \mathrm{O}_{3}$ in the passive state that re-formed between 309 and $316 \mathrm{~h}$ was much stronger than that which was formed first between 42 and $186 \mathrm{~h}$. We changed the vacuum level from $2.0 \times 10^{-7}$ to $1.0 \times 10^{-7} \mathrm{~Pa}$ at $356 \mathrm{~h}$. The common logarithm of the photocurrent then increased at a rate of $+0.00305 / \mathrm{h}$ between 356 and $378 \mathrm{~h}$. An increase in the photocurrent from a $\mathrm{Cs}_{3} \mathrm{Sb}$ photocathode has not been reported to date. This phenomenon is extraordinary and is not yet understood.

We applied continuous irradiation by a $405 \mathrm{~nm}$ laser between 378 and $430 \mathrm{~h}$. The common logarithm of the photocurrent decreased rapidly (at a rate of $-0.184 / \mathrm{h}$ ) between 378 and $378.5 \mathrm{~h}$, but the rate decreased gradually after $378.5 \mathrm{~h}$. The common logarithm of the photocurrent decreased more slowly (at a rate of $-0.0192 / \mathrm{h}$ ) between 383 and 385 h. As shown in Fig. 14, we increased the laser intensity at the cathode tip from 0.16 to $0.52 \mathrm{~W} / \mathrm{cm}^{2}$ at $385 \mathrm{~h}$. The common logarithm of the photocurrent then decreased rapidly (at a rate of $-0.0859 / \mathrm{h}$ ) between 385 and $386 \mathrm{~h}$, but it decreased more slowly after $386 \mathrm{~h}$. The common logarithm of the photocurrent decreased at a rate of 0.00530/h between 402 and $405 \mathrm{~h}$. At $405 \mathrm{~h}$, we reduced the vacuum level from $1.0 \times$ $10^{-7}$ to $2.0 \times 10^{-7} \mathrm{~Pa}$ and changed the laser intensity at the cathode tip from 0.52 to $0.15 \mathrm{~W} / \mathrm{cm}^{2}$. Then the common logarithm of the photocurrent decreased rapidly (at a rate of $-0.116 / \mathrm{h}$ ) between 405 and $406 \mathrm{~h}$, and it decreased at a rate of $-0.0493 / \mathrm{h}$ between 407 and $409 \mathrm{~h}$. We increased the laser intensity at the cathode tip from 0.15 to $0.53 \mathrm{~W} / \mathrm{cm}^{2}$ at $409 \mathrm{~h}$. The common logarithm of the photocurrent then decreased at a rate of $-0.0647 / \mathrm{h}$ between 409 and $411 \mathrm{~h}$, but the rate decreased gradually after $411 \mathrm{~h}$. The common logarithm of the photocurrent decreased at a rate of $-0.0172 / \mathrm{h}$ between 425 and $428 \mathrm{~h}$.

We further reduced the vacuum level from $2.0 \times 10^{-7}$ to $3.9 \times 10^{-7} \mathrm{~Pa}$ and stopped the continuous laser irradiation at $428 \mathrm{~h}$. The common logarithm of the photocurrent then decreased rapidly (at a rate of $-0.0814 / \mathrm{h}$ ) between 428 and $430 \mathrm{~h}$. However, the rate decreased at $430 \mathrm{~h}$, and it was $-0.0224 / \mathrm{h}$ between 430 and $450 \mathrm{~h}$. The common logarithm of the photocurrent decreased rapidly (at a rate of $-0.0923 / \mathrm{h}$ ) between 450 and $453 \mathrm{~h}$. We think that the rate of decrease between 430 and $450 \mathrm{~h}$ was smaller than those in the preceding and following periods because we did not measure the photocurrent between 430 and $450 \mathrm{~h}$. We again started continuous laser irradiation at 
a laser intensity of $0.18 \mathrm{~W} / \mathrm{cm}^{2}$ at the cathode tip at $453 \mathrm{~h}$. The common logarithm of the photocurrent then decreased very rapidly (at a rate of $0.286 / \mathrm{h}$ ) between 453 and $454 \mathrm{~h}$.

Table 4 summarizes the experimental results regarding the effects of surface protection of the $\mathrm{Cs}_{3} \mathrm{Sb}$ photocathode by $\mathrm{WO}_{3}$ or $\mathrm{Cr}_{2} \mathrm{O}_{3}$ in the passive state. For each experiment, we show the vacuum level, laser irradiation condition, rate at which the common logarithm of the photocurrent decreased before and after formation of $\mathrm{WO}_{3}$ or $\mathrm{Cr}_{2} \mathrm{O}_{3}$, and temperature of the chamber. We compare the rate at which the common logarithm of the photocurrent decreased before and after formation of $\mathrm{WO}_{3}$ or $\mathrm{Cr}_{2} \mathrm{O}_{3}$ in the passive state. In this table, $G_{\mathrm{A}} / G_{\mathrm{B}}$ is the ratio of the rate of decrease of the common logarithm of the photocurrent after formation of $\mathrm{WO}_{3}$ or $\mathrm{Cr}_{2} \mathrm{O}_{3}$ in the passive state to that before its formation. Therefore, $G_{\mathrm{A}} / G_{\mathrm{B}}$ is an index of the strength of the surface protection of the $\mathrm{Cs}_{3} \mathrm{Sb}$ photocathode by $\mathrm{WO}_{3}$ or $\mathrm{Cr}_{2} \mathrm{O}_{3}$ in the passive state. If $G_{\mathrm{A}} / G_{\mathrm{B}}$ is small, the effect of surface protection by $\mathrm{WO}_{3}$ or $\mathrm{Cr}_{2} \mathrm{O}_{3}$ in the passive state is large.

As shown in table $4, G_{\mathrm{A}} / G_{\mathrm{B}}$ was 0.605 for the $\mathrm{WO}_{3}$ in the passive state formed from the one-atomic-layer $\mathrm{W}$ film in experiment $\mathrm{I}$, and it was 0.0114 for the $\mathrm{WO}_{3}$ in the passive state formed from the three-atomic-layer $\mathrm{W}$ film in experiment II. Both ratios were taken under intermittent laser irradiation. Therefore, the $\mathrm{WO}_{3}$ in the passive state formed from the three-atomic-layer $\mathrm{W}$ film in experiment II protected the surface of the $\mathrm{Cs}_{3} \mathrm{Sb}$ photocathode much more effectively than that formed from the one-atomic-layer $\mathrm{W}$ film in experiment I. This result is quite reasonable because the thicker oxide film in the passive state could protect the surface of the $\mathrm{Cs}_{3} \mathrm{Sb}$ photocathode more effectively. If the absorption of photoelectrons by $\mathrm{WO}_{3}$ in the passive state is negligible, the effectiveness of surface protection by $\mathrm{WO}_{3}$ in the passive state increases with increasing $\mathrm{WO}_{3}$ thickness.

For intermittent laser irradiation, the $G_{\mathrm{A}} / G_{\mathrm{B}}$ value of the $\mathrm{Cr}_{2} \mathrm{O}_{3}$ in the passive state formed from the one-atomic-layer $\mathrm{Cr}$ film in experiment III was 0.187 , that of the film formed from the one-atomic-layer $\mathrm{Cr}$ film in experiment IV was 0.739 , that of the film formed from the two-atomic-layer $\mathrm{Cr}$ film in experiment VI was 0.479 , and that of the film formed from the three-atomic-layer $\mathrm{Cr}$ film in experiment VII was 0.000832 . For continuous laser irradiation, the $G_{\mathrm{A}} / G_{\mathrm{B}}$ value of the $\mathrm{Cr}_{2} \mathrm{O}_{3}$ in the passive state formed from the 1.5-atomic-layer $\mathrm{Cr}$ film in experiment $\mathrm{V}$ was 0.181 , and that of the film formed from the three-atomic-layer $\mathrm{Cr}$ film in experiment VIII was 0.0528 . These results imply that thicker $\mathrm{Cr}_{2} \mathrm{O}_{3}$ in the passive state protects the surface of the $\mathrm{Cs}_{3} \mathrm{Sb}$ photocathode more effectively. This tendency is the same as that for $\mathrm{WO}_{3}$ in the passive state. If the absorption of photoelectrons by $\mathrm{Cr}_{2} \mathrm{O}_{3}$ in the passive state is negligible, therefore, the effectiveness of surface protection by $\mathrm{Cr}_{2} \mathrm{O}_{3}$ in the passive state increases 
with increasing $\mathrm{Cr}_{2} \mathrm{O}_{3}$ thickness. The difference in $G_{\mathrm{A}} / G_{\mathrm{B}}$ between experiments III and IV was caused by the difference in the rate $G_{\mathrm{B}}$ between them. As shown in table 4 , the temperature of the upper chamber was $27^{\circ} \mathrm{C}$ in experiment III, but it was $7-26^{\circ} \mathrm{C}$ in experiment IV. We think the difference in the temperature of the upper chamber caused the difference in $G_{\mathrm{B}}$ between the experiments because the higher temperature produced more $\mathrm{H}_{2} \mathrm{O}$ vapor, which enhanced oxidization of the $\mathrm{Cs}_{3} \mathrm{Sb}$ photocathode. When we took the data for $G_{\mathrm{A}}$, on the other hand, the temperature of the upper chamber was approximately $27^{\circ} \mathrm{C}$ in both experiments. This is consistent with the result that $G_{\mathrm{A}}$ was almost the same in the two experiments, as shown in table 4.

When we compare the effectiveness of surface protection of the $\mathrm{Cs}_{3} \mathrm{Sb}$ photocathode by $\mathrm{WO}_{3}$ in the passive state and by $\mathrm{Cr}_{2} \mathrm{O}_{3}$ in the passive state, we should adopt the ratio $G_{\mathrm{A}} / G_{\mathrm{B}}=0.187$ from experiment III as the ratio for the one-atomic-layer $\mathrm{Cr}$ film, for the reason given above. Therefore, as shown in table 4, the $\mathrm{Cr}_{2} \mathrm{O}_{3}$ in the passive state formed from the one-atomic-layer $\mathrm{Cr}$ film protected the surface of the $\mathrm{Cs}_{3} \mathrm{Sb}$ photocathode more effectively than the $\mathrm{WO}_{3}$ formed from the one-atomic-layer W film. Because the $G_{\mathrm{A}} / G_{\mathrm{B}}$ value of 0.00382 in experiment VII was smaller than that in experiment II, 0.0114, the $\mathrm{Cr}_{2} \mathrm{O}_{3}$ in the passive state formed from the three-atomic-layer $\mathrm{Cr}$ film protected the surface more effectively than the $\mathrm{WO}_{3}$ from the three-atomic-layer W film. Therefore, we conclude that $\mathrm{Cr}_{2} \mathrm{O}_{3}$ in the passive state protects the surface of the $\mathrm{Cs}_{3} \mathrm{Sb}$ photocathode more effectively than $\mathrm{WO}_{3}$ in the passive state, if these oxide films are formed from films having the same number of atomic layers.

Because the protection of the surface of the $\mathrm{Cs}_{3} \mathrm{Sb}$ photocathode by $\mathrm{Cr}_{2} \mathrm{O}_{3}$ in the passive state was not sufficient for use of the cathode at the vacuum level in typical TEMs, we abandoned the use of the cathode tip coated with the $\mathrm{Cs}_{3} \mathrm{Sb}$ photocathode in the modified TEM shown in Fig. 2. However, we found that $\mathrm{Cr}_{2} \mathrm{O}_{3}$ in the passive state provides stronger surface protection as its thickness increases. We hope that in future the protective effect of $\mathrm{Cr}_{2} \mathrm{O}_{3}$ in the passive state formed from a $\mathrm{Cr}$ film that is reasonably thick will be sufficient for use at the vacuum level of TEMs.

\section{Conclusions}

We examined 1) the photocurrent as a function of anode voltage below $200 \mathrm{~V}$, 2) the relationship between the quantum efficiency and the conditions under which $\mathrm{Cs}_{3} \mathrm{Sb}$ photocathodes were fabricated by the so-called sandwich method, 3) recovery of the photoemission of $\mathrm{Cs}_{3} \mathrm{Sb}$ photocathodes by additional $\mathrm{Cs}$ deposition, and 4) the protective effect of $\mathrm{WO}_{3}$ and $\mathrm{Cr}_{2} \mathrm{O}_{3}$ in the passive state on the surface of $\mathrm{Cs}_{3} \mathrm{Sb}$ 
photocathodes.

We found that the photocurrent was significantly affected by the rate of increase of the anode voltage used to extract photoelectrons. When we increased it at a typical speed, the photocurrent increased with increasing voltage from 0 to $68 \mathrm{~V}$, but it decreased gradually from 68 to $196 \mathrm{~V}$. When we increased it very slowly, however, the photocurrent decreased gradually with increasing voltage from 24 to $93 \mathrm{~V}$, but it increased steeply when the voltage was around $98 \mathrm{~V}$.

We found that three conditions are necessary to fabricate $\mathrm{Cs}_{3} \mathrm{Sb}$ photocathodes with higher quantum efficiency using the sandwich method. First, we have to increase the cathode temperature smoothly after the second $\mathrm{Sb}$ deposition at low temperature. Second, we have to start increasing the cathode temperature as soon as possible after the second $\mathrm{Sb}$ deposition. Third, we have to increase the cathode temperature to $25-40^{\circ} \mathrm{C}$ after the second $\mathrm{Sb}$ deposition.

We also identified the conditions for effective recovery of photoemission from $\mathrm{Cs}_{3} \mathrm{Sb}$ photocathodes by additional Cs deposition. First, we have to deposit $\mathrm{Cs}$ at a cathode temperature of $50-70^{\circ} \mathrm{C}$ to effectively increase the photoemission. Second, we have to gradually decrease the cathode temperature to within $40-45^{\circ} \mathrm{C}$ to minimize the reduction in photocurrent after additional Cs deposition. We think that installation of a device for evacuation of Cs within a TEM would be very helpful to realize the use of $\mathrm{Cs}_{3} \mathrm{Sb}$ photocathodes in TEMs.

We examined in detail the effect of surface protection of the $\mathrm{Cs}_{3} \mathrm{Sb}$ photocathode by $\mathrm{WO}_{3}$ or $\mathrm{Cr}_{2} \mathrm{O}_{3}$ in the passive state during lifetime tests in eight experiments. We found that deposition of a 1- or 3-atomic-layer W film and of a 1-, 1.5-, 2-, or 3-atomic-layer Cr film greatly extended the lifetime of photoemission from the $\mathrm{Cs}_{3} \mathrm{Sb}$ photocathode after the $\mathrm{W}$ or $\mathrm{Cr}$ film was oxidized to $\mathrm{WO}_{3}$ or $\mathrm{Cr}_{2} \mathrm{O}_{3}$ in the passive state. The protective effect of $\mathrm{WO}_{3}$ or $\mathrm{Cr}_{2} \mathrm{O}_{3}$ in the passive state on the surface of the $\mathrm{Cs}_{3} \mathrm{Sb}$ photocathode became stronger after both further oxidation under lower vacuum and photo-oxidation during continuous laser irradiation. We concluded that the effect of surface protection by a $\mathrm{WO}_{3}$ or $\mathrm{Cr}_{2} \mathrm{O}_{3}$ film in the passive state increases with increasing film thickness. We also concluded that $\mathrm{Cr}_{2} \mathrm{O}_{3}$ in the passive state protects the surface of the $\mathrm{Cs}_{3} \mathrm{Sb}$ photocathode more effectively than $\mathrm{WO}_{3}$ in the passive state, if these oxide films are formed from films having the same number of atomic layers.

\section{Acknowledgements}

We gratefully acknowledge the funding from the Japan Science and 
Technology Agency (JST) under the "Core Research for Evolution Science and Technology (CREST)" program. We would like to thank Editage (www.editage.jp) for English language editing.

\section{References}

[1] W.E. Spicer, Physical Review 112 (1958) 14.

[2] J. C. H Spence, J. M. Zuo, Electron Microdiffraction (Plenum Press, New York, 1992).

[3] A. H. Sommer, Photoemissive Materials, Wiley, New York, 1968.

[4]T. Kimoto, Y. Arai, K. Nagata, Applied Surface Science 258 (2012) 5646.

[5] L. R. Danielson, C. Lee, P. E. Oettinger, Applied Surface Science 16 (1983) 257.

[6] A. Buzulutskov, A. Breskin, R. Chechik, M. Prager, E. Shefer, Nuclear Instruments and Methods in Physics Research Section A 387 (1997) 176.

[7] A. Buzulutskov, E. Shefer, A. Breskin, R. Chechik, M. Prager, Nuclear Instruments and Methods in Physics Research Section A 400 (1997) 173.

[8] E. Shefer, A. Breskin, A. Buzulutskov, R. Chechik, M. Prager, Nuclear Instruments and Methods in Physics Research Section A 419 (1998) 612.

[9] E. Shefer, A. Breskin, R. Chechik, A. Buzulutskov, B. K. Singh, M. Prager, Nuclear Instruments and Methods in Physics Research Section A 433 (1999) 502.

[10] T. Kimoto, Y. Arai, X. Ren, Applied Surface Science 284 (2013) 657.

[11] W. E. Spicer, RCA Review 19 (1958) 555.

[12] W. E. Spicer, F. Wooten, Proceedings of the IEEE51 (1963)1127.

Figure Captions

Fig. 1 Developed vacuum deposition device for fabricating $\mathrm{Cs}_{3} \mathrm{Sb}$ photocathode on a small area of a fine cathode tip under high vacuum.

Fig. 2 Modified TEM, which enables us to introduce a photocathode into its electron gun from the enclosed capsule in Ar gas atmosphere.

Fig. 3 Schematic diagram of fabrication of $\mathrm{Cs}_{3} \mathrm{Sb}$ on a cathode tip and coating of $\mathrm{W}$ or $\mathrm{Cr}$ thin film on the surface of $\mathrm{Cs}_{3} \mathrm{Sb}$. (a) Successive deposition of $\mathrm{Cr}, \mathrm{Sb}, \mathrm{Cs}$, and $\mathrm{Sb}$, 
and their planned thicknesses. (b) Formation of $\mathrm{Cs}_{3} \mathrm{Sb}$ by increasing the cathode temperature from -16 to $-12^{\circ} \mathrm{C}$ to $6-40^{\circ} \mathrm{C}$. (c) Deposition of $\mathrm{W}$ or $\mathrm{Cr}$ thin film to protect $\mathrm{Cs}_{3} \mathrm{Sb}$ during the lifetime test.

Fig. 4 Normalized photocurrent as a function of anode voltage below $196 \mathrm{~V}$, which was obtained at elapsed time of $82 \mathrm{~h}$ in the lifetime test in experiment II. Data were obtained by increasing the voltage from 9 to $196 \mathrm{~V}$ for $35 \mathrm{~min}$ in increments of about 10 $\mathrm{V}$.

Fig. 5 Normalized photocurrent as a function of anode voltage below $196 \mathrm{~V}$, which was obtained at elapsed time of $175 \mathrm{~h}$ in the lifetime test in experiment II. Data were obtained by increasing the voltage very gradually from 3 to $196 \mathrm{~V}$ for $61.5 \mathrm{~min}$ in increments of approximately $5 \mathrm{~V}$.

Fig. 6 Temperature of the cathode tip as a function of elapsed time (min) from the second $\mathrm{Sb}$ deposition to the first detection of photoelectrons in experiments I, IV, V, and VIII, where the first detected quantum efficiencies were initially smaller than $1 \%$.

Fig. 7 Temperature of the cathode tip as a function of elapsed time (min) from the second $\mathrm{Sb}$ deposition to the first detection of photoelectrons for experiments II, III, VI, and VII, where the first detected quantum efficiencies were larger than $1 \%$.

Fig. 8 Normalized photocurrent and cathode temperature as a function of elapsed time during additional $\mathrm{Cs}$ deposition in experiment $\mathrm{I}$. The time $0 \mathrm{~min}$ corresponds to the elapsed time of $46 \mathrm{~h}$ in the lifetime test, and the vacuum level during additional deposition of Cs was 1.6-2.5 $\times 10^{-7} \mathrm{~Pa}$.

Fig. 9 Normalized photocurrent and cathode temperature as a function of elapsed time during additional $\mathrm{Cs}$ deposition in experiment $\mathrm{V}$. The time 0 min corresponds to 1 $\mathrm{h}$ before the lifetime test began, and the vacuum level during additional deposition of $\mathrm{Cs}$ was $1.6-2.0 \times 10^{-7} \mathrm{~Pa}$.

Fig. 10 Normalized photocurrent and cathode temperature as a function of elapsed time during additional $\mathrm{Cs}$ deposition in experiment VII. The time 0 min corresponds to the elapsed time of $23 \mathrm{~h}$ in the lifetime test, and the vacuum level during additional deposition of Cs was 1.0-1.1 $\times 10^{-7} \mathrm{~Pa}$. 
Fig. 11 Common logarithm of normalized photocurrent as a function of elapsed time from 0 to $190 \mathrm{~h}$ in lifetime test of $\mathrm{Cs}_{3} \mathrm{Sb}$ photocathode in experiment II. The intensity of the $405 \mathrm{~nm}$ laser at the cathode tip during continuous laser irradiation and continuous electron emission, the vacuum level, and the time of $\mathrm{W}$ deposition are shown.

Fig. 12 Common logarithm of normalized photocurrent as a function of elapsed time from 190 to $347 \mathrm{~h}$ in lifetime test of $\mathrm{Cs}_{3} \mathrm{Sb}$ photocathode in experiment II. The intensity of the $405 \mathrm{~nm}$ laser at the cathode tip during continuous laser irradiation, and the vacuum level are shown. This figure continues Fig. 11.

Fig. 13 Common logarithm of normalized photocurrent as a function of elapsed time from 0 to $250 \mathrm{~h}$ in lifetime test of $\mathrm{Cs}_{3} \mathrm{Sb}$ photocathode in experiment VII. The vacuum level, and the times of additional Cs deposition and $\mathrm{Cr}$ deposition are shown.

Fig. 14 Common logarithm of normalized photocurrent as a function of elapsed time from 250 to $455 \mathrm{~h}$ in lifetime test of $\mathrm{Cs}_{3} \mathrm{Sb}$ photocathode in experiment VII. The intensities of the 405-nm laser at the cathode tip during the continuous laser irradiation, and the vacuum level are also shown. This figure continues Fig. 13. 
Table 1 Summarization of experimental conditions.

\begin{tabular}{|c|c|c|c|c|c|c|c|c|}
\hline \multirow{2}{*}{$\begin{array}{l}\text { Experiment } \\
\text { Number }\end{array}$} & \multirow{2}{*}{$\begin{array}{l}\text { Deposited } \\
\text { film }\end{array}$} & \multicolumn{3}{|c|}{ Baking before $\mathrm{Cs}_{3} \mathrm{Sb}$ formation } & \multicolumn{4}{|c|}{ Photoemission lifetime test } \\
\hline & & Period (h) & $\begin{array}{l}\text { Temperature } \\
\left({ }^{\circ} \mathrm{C}\right)\end{array}$ & Period (h) & $\begin{array}{c}\text { Additional Cs } \\
\text { deposition time } \\
t_{\mathrm{Cs}}\end{array}$ & $\begin{array}{l}\mathrm{W} \text { or } \mathrm{Cr} \\
\text { deposition time } \\
t_{\mathrm{W}} \text { or } t_{\mathrm{Cr}}\end{array}$ & $\begin{array}{l}\text { Vacuum level } \\
\qquad(\mathrm{Pa})\end{array}$ & $\begin{array}{l}\text { Vacuum } \\
\text { pump }\end{array}$ \\
\hline I & $\mathrm{W}: 1$ at. layer & 48 & $121-142$ & 219 & $t_{\mathrm{Cs}}=46 \mathrm{~h}$ & $t_{\mathrm{W}}=120 \mathrm{~h}$ & $1.2-2.2 \times 10^{-7}$ & TMP \\
\hline II (Fig.4\&5) & W: 3 at. layer & 664 & $101-118$ & 357 & $t_{\mathrm{Cs}}=-18 \mathrm{~h}$ & $t_{\mathrm{W}}=9 \mathrm{~h}$ & $1.0-2.1 \times 10^{-7}$ & Cryo + TMP \\
\hline III & Cr: 1 at. layer & 500 & $101-113$ & 221 & $t_{\mathrm{Cs}}=144 \mathrm{~h}$ & $t_{\mathrm{Cr}}=164 \mathrm{~h}$ & $1.8-3.0 \times 10^{-7}$ & TMP \\
\hline IV & Cr: 1 at. layer & 546 & $103-114$ & 217 & $t_{\mathrm{Cs}}=-1 \mathrm{~h}$ & $t_{\mathrm{Cr}}=162 \mathrm{~h}$ & $1.8-3.4 \times 10^{-7}$ & TMP \\
\hline $\mathrm{V}$ & Cr: 1.5 at. layer & 670 & $102-109$ & 240 & $t_{\mathrm{Cs}}=-1 \mathrm{~h}$ & $t_{\mathrm{Cr}}=2 \mathrm{~h}$ & $1.2-2.0 \times 10^{-7}$ & Cryo + TMP \\
\hline VI & Cr: 2 at. layer & 214 & $109-119$ & 383 & $t_{\mathrm{Cs}}=140 \mathrm{~h}$ & $t_{\mathrm{Cr}}=164 \mathrm{~h}$ & $1.8-3.5 \times 10^{-7}$ & TMP \\
\hline VII & Cr: 3 at. layer & 188 & $105-115$ & 455 & $t_{\mathrm{Cs}}=215 \mathrm{~h}$ & $t_{\mathrm{Cr}}=23 \mathrm{~h}$ & $1.1-3.9 \times 10^{-7}$ & Cryo + TMP \\
\hline VIII & Cr: 3 at. layer & 1940 & $116-123$ & 218 & $t_{\mathrm{Cs}}=23 \mathrm{~h}$ & $t_{\mathrm{Cr}}=142 \mathrm{~h}$ & $1.4-3.1 \times 10^{-7}$ & TMP \\
\hline
\end{tabular}


Table 2 Summarized results about fabrication of $\mathrm{Cs}_{3} \mathrm{Sb}$ by the sandwich method.

\begin{tabular}{|c|c|c|c|c|}
\hline $\begin{array}{l}\text { Experiment } \\
\text { Number }\end{array}$ & $\begin{array}{l}\text { Deposited } \\
\text { Film }\end{array}$ & $\begin{array}{c}\text { Quantum efficiency (\%) } \\
\left(t \text { min after } 2^{\text {nd }} \text { Sb addition) }\right.\end{array}$ & $\begin{array}{l}\text { Cathode temperature change } \\
\text { from } 2^{\text {nd }} \text { Sb addition } \\
\text { to photocurrent detection }\end{array}$ & $\begin{array}{l}\text { Vacuum level } \\
\text { at cathode tip } \\
\qquad(\mathrm{Pa})\end{array}$ \\
\hline I & $\mathrm{W}: 1$ at. layer & $0.319 \quad(t=53)$ & $-12^{\circ} \mathrm{C} \rightarrow 40^{\circ} \mathrm{C}$ & $1.2 \times 10^{-7}$ \\
\hline II & $\mathrm{W}: 3$ at. layer & $4.95 \quad(t=21)$ & $-18^{\circ} \mathrm{C} \rightarrow 25^{\circ} \mathrm{C}$ & $1.2 \times 10^{-7}$ \\
\hline III & Cr: 1 at. layer & $2.58 \quad(t=33)$ & $-16^{\circ} \mathrm{C} \rightarrow 7^{\circ} \mathrm{C}$ & $1.8 \times 10^{-7}$ \\
\hline VI & Cr: 1 at. layer & $0.0385(t=38)$ & $-15^{\circ} \mathrm{C} \rightarrow 6^{\circ} \mathrm{C}$ & $1.8 \times 10^{-7}$ \\
\hline $\mathrm{V}$ & Cr: 1.5 at. layer & $0.452 \quad(t=45)$ & $-16^{\circ} \mathrm{C} \rightarrow 29^{\circ} \mathrm{C}$ & $1.3 \times 10^{-7}$ \\
\hline VI & Cr: 2 at. layer & $9.17 \quad(t=53)$ & $-12^{\circ} \mathrm{C} \rightarrow 37^{\circ} \mathrm{C}$ & $1.7 \times 10^{-7}$ \\
\hline VII & Cr: 3 at. layer & $1.06 \quad(t=53)$ & $-12^{\circ} \mathrm{C} \rightarrow 37^{\circ} \mathrm{C}$ & $1.2 \times 10^{-7}$ \\
\hline VIII & Cr: 3 at. layer & $0.510 \quad(t=53)$ & $-15^{\circ} \mathrm{C} \rightarrow 35^{\circ} \mathrm{C}$ & $1.3 \times 10^{-7}$ \\
\hline
\end{tabular}


Table 3 Summarized results regarding the recovery of photoemission from $\mathrm{Cs}_{3} \mathrm{Sb}$ photocathodes by additional Cs deposition.

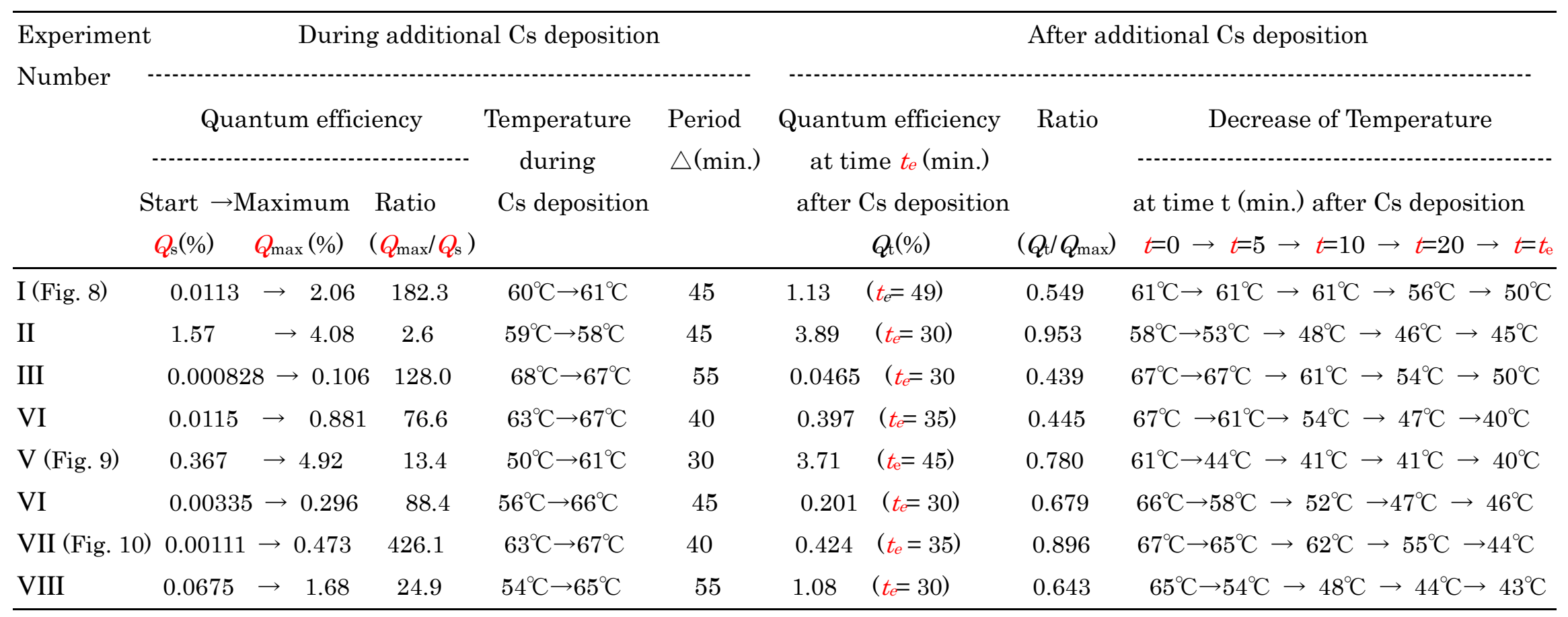


Table 4 Summarization of the experimental results regarding the effects of surface protection of the $\mathrm{Cs}_{3} \mathrm{Sb}_{\mathrm{S}}$ photocathode by $\mathrm{WO}_{3}$ or $\mathrm{CrO}_{3}$ in the passive state. "Cryo" means a cryopump.

\begin{tabular}{|c|c|c|c|c|c|}
\hline \multirow{3}{*}{$\begin{array}{l}\text { Experiment } \\
\text { Number }\end{array}$} & \multirow{3}{*}{$\begin{array}{l}\text { Deposited } \\
\text { film }\end{array}$} & \multicolumn{4}{|c|}{ Experimental conditions and corresponding results during life time test } \\
\hline & & \multirow[t]{2}{*}{$\begin{array}{l}\text { Vacuum }(\mathrm{Pa}) \\
\text { [Pumping] }\end{array}$} & \multicolumn{3}{|c|}{$\begin{array}{l}\text { Rate with which common logarithm of the photocurrent decreased } \\
\text { before and after formation of } \mathrm{WO}_{3} \text { or } \mathrm{Cr}_{2} \mathrm{O}_{3} \text {, and [chamber temperature }\end{array}$} \\
\hline & & & Before $\left(G_{\mathrm{B}}\right)[$ Temp.] - & $\rightarrow \quad \operatorname{After}\left(G_{\mathrm{A}}\right)[$ Temp.] & Ratio $\left(G_{\mathrm{A}} / G_{\mathrm{B}}\right)$ \\
\hline $\mathrm{I}$ & $\mathrm{W}: 1$ at. layer & $1.2 \times 10^{-7}[$ Cryo $] \quad$ Intermittent & $0.00671 / \mathrm{h}\left[6-7^{\circ} \mathrm{C}\right]$ & $\rightarrow \quad 0.00406 / \mathrm{h}\left[7^{\circ} \mathrm{C}\right]$ & 0.605 \\
\hline II (Fig.11\&12) & $\mathrm{W}: 3$ at. layer & $2.0 \times 10^{-7}[\mathrm{TMP}] \quad$ Intermittent & $0.309 / \mathrm{h} \quad\left[25^{\circ} \mathrm{C}\right]$ & $\rightarrow \quad 0.00353 / \mathrm{h}\left[25^{\circ} \mathrm{C}\right]$ & 0.0114 \\
\hline III & Cr: 1 at. layer & $1.8 \times 10^{-7}[\mathrm{TMP}] \quad$ Intermittent & $0.0852 / \mathrm{h} \quad\left[27^{\circ} \mathrm{C}\right]$ & $\rightarrow \quad 0.0159 / \mathrm{h}\left[27^{\circ} \mathrm{C}\right]$ & 0.187 \\
\hline VI & Cr: 1 at. layer & $1.9 \times 10^{-7}[\mathrm{TMP}] \quad$ Intermittent & $0.0207 / \mathrm{h} \quad\left[7-26^{\circ} \mathrm{C}\right]$ & $\rightarrow \quad 0.0153 / \mathrm{h}\left[27^{\circ} \mathrm{C}\right]$ & 0.739 \\
\hline $\mathrm{V}$ & Cr: 1.5 at. layer & $\begin{array}{r}1.0 \times 10^{-7}[\text { Cryo }] \text { Continuous } \\
\left(0.00366 \mathrm{~W} / \mathrm{cm}^{2}\right)\end{array}$ & $0.0341 / \mathrm{h} \quad\left[7^{\circ} \mathrm{C}\right]$ & $\rightarrow \quad 0.00618 / \mathrm{h}\left[7^{\circ} \mathrm{C}\right]$ & 0.181 \\
\hline VI & Cr: 2 at. layer & $1.6 \times 10^{-7}[\mathrm{TMP}] \quad$ Intermittent & $0.0145 / \mathrm{h}\left[7^{\circ} \mathrm{C}\right]$ & $\rightarrow \quad 0.00695 / \mathrm{h}\left[28^{\circ} \mathrm{C}\right]$ & 0.479 \\
\hline VII(Fig.13\&14) & Cr: 3 at. layer & $2.0 \times 10^{-7}[\mathrm{TMP}] \quad$ Intermittent & $0.218 / \mathrm{h} \quad\left[5^{\circ} \mathrm{C}\right]$ & $\rightarrow \quad 0.000832 / \mathrm{h}\left[5^{\circ} \mathrm{C}\right]$ & 0.00382 \\
\hline VIII & Cr: 3 at. layer & $\begin{array}{r}1.5 \times 10^{-7}[\mathrm{TMP}] \quad \text { Continuous } \\
\left(0.0127 \mathrm{~W} / \mathrm{cm}^{2}\right)\end{array}$ & $0.184 / \mathrm{h} \quad\left[7^{\circ} \mathrm{C}\right]$ & $\rightarrow \quad 0.00972 / \mathrm{h}\left[7^{\circ} \mathrm{C}\right]$ & 0.0528 \\
\hline
\end{tabular}




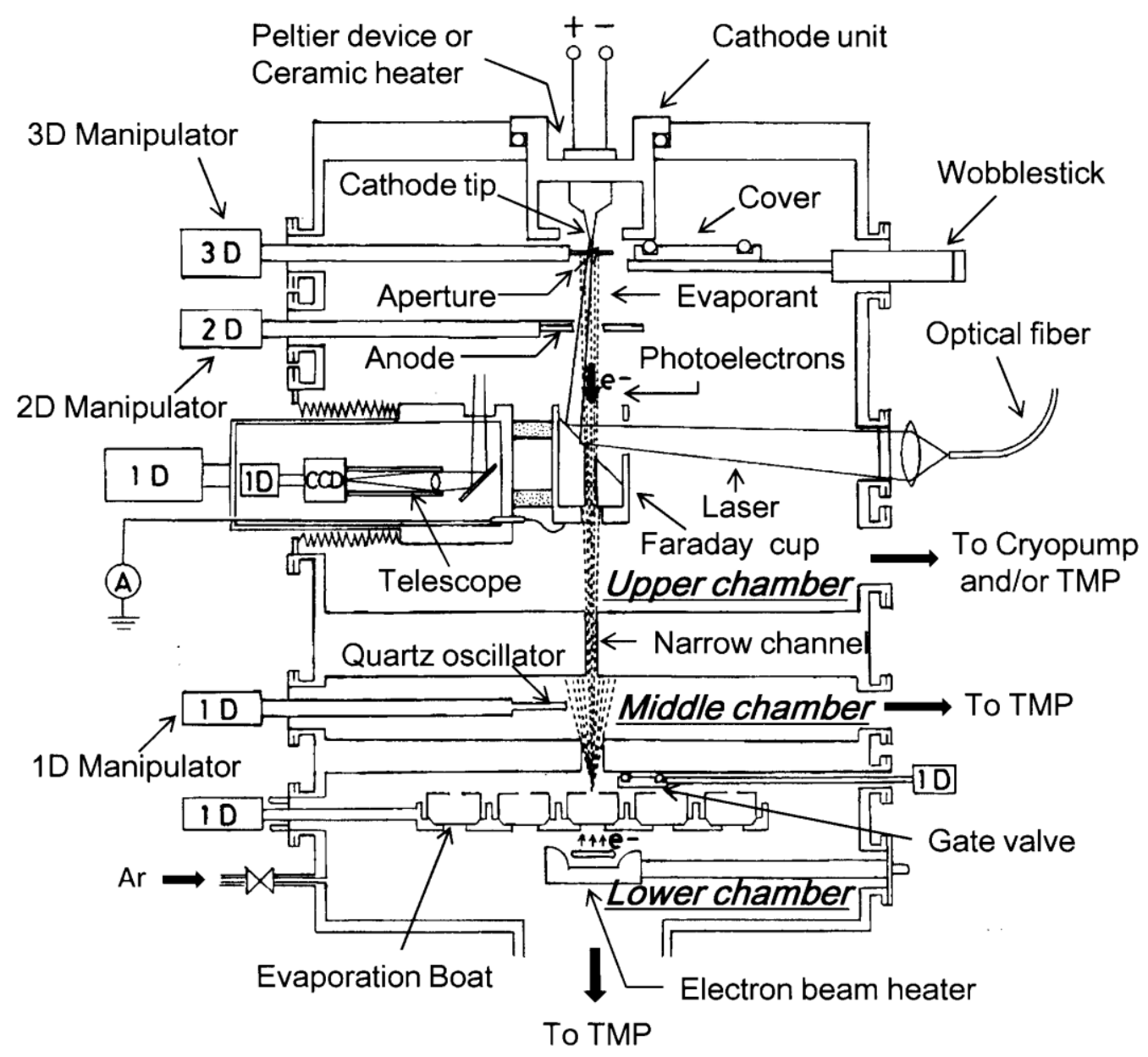

Fig. 1 Developed vacuum deposition device for fabricating $\mathrm{Cs}_{3} \mathrm{Sb}$ photocathode on a small area of a fine cathode tip under high vacuum. 

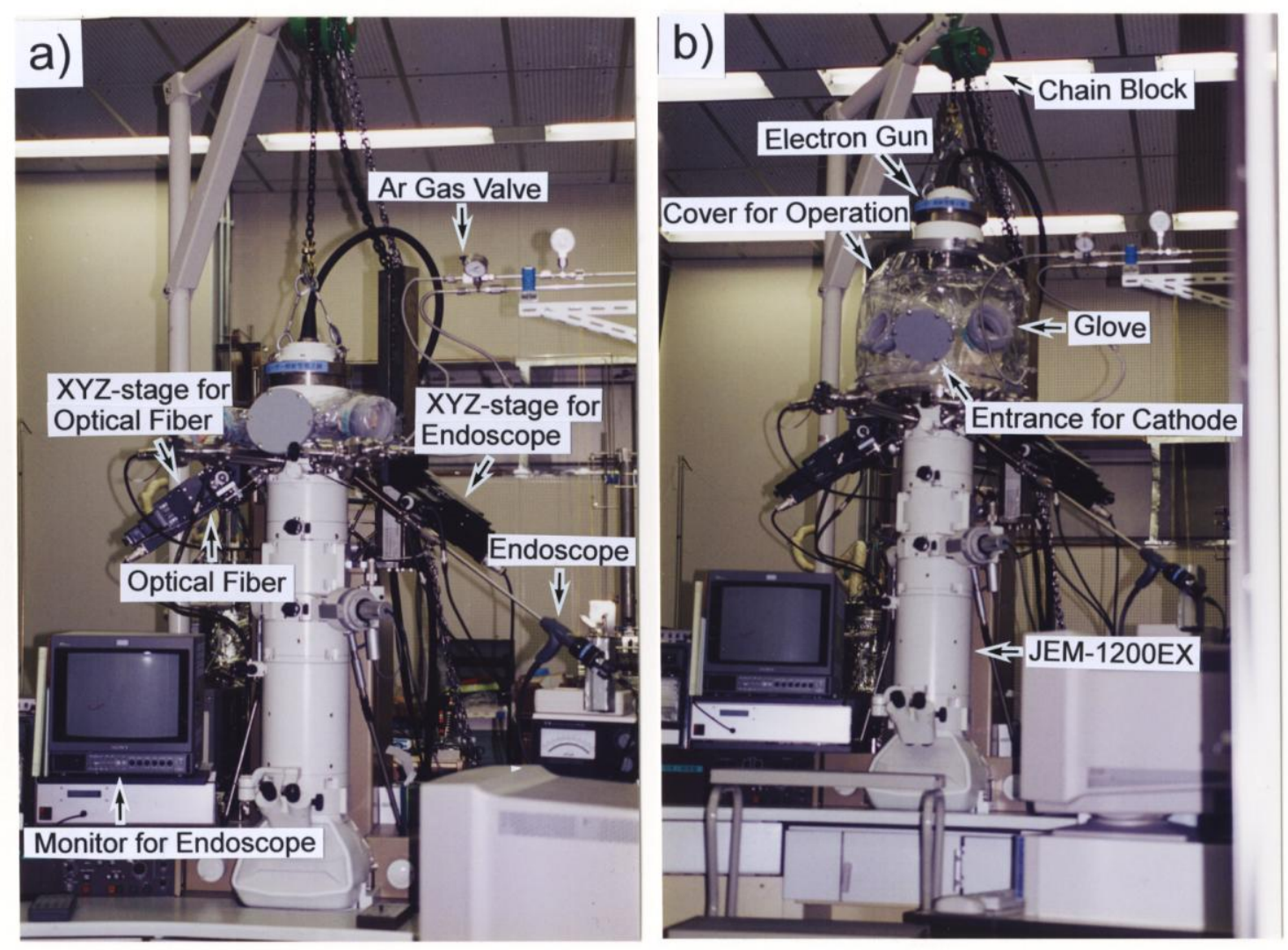

Fig. 2 Modified TEM, which enables us to introduce a photocathode into its electron gun from the enclosed capsule in Ar gas atmosphere. 
a)

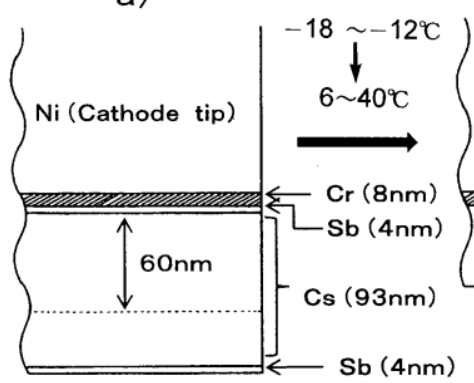

b)

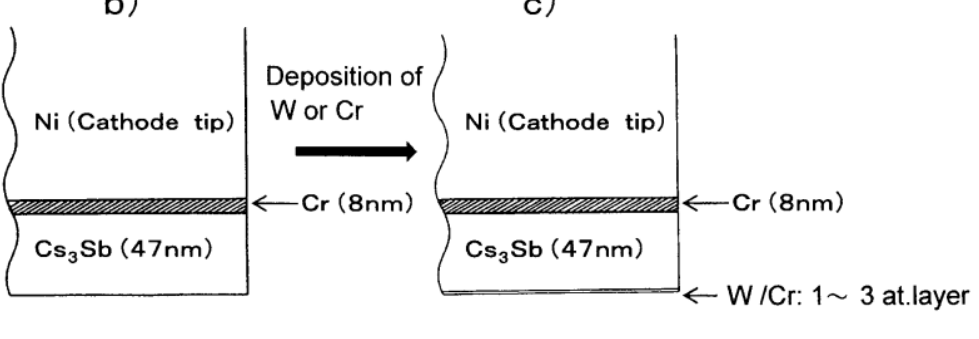

Fig. 3 Schematic diagram of fabrication of $\mathrm{Cs}_{3} \mathrm{Sb}$ on a cathode tip and coating of $\mathrm{W}$ or $\mathrm{Cr}$ thin film on the surface of $\mathrm{Cs}_{3} \mathrm{Sb}$. (a) Successive deposition of $\mathrm{Cr}, \mathrm{Sb}, \mathrm{Cs}$, and $\mathrm{Sb}$, and their planned thicknesses. (b) Formation of $\mathrm{Cs}_{3} \mathrm{Sb}$ by increasing the cathode temperature from -16 to $-12^{\circ} \mathrm{C}$ to $6-40^{\circ} \mathrm{C}$. (c) Deposition of $\mathrm{W}$ or $\mathrm{Cr}$ thin film to protect $\mathrm{Cs}_{3} \mathrm{Sb}$ during the lifetime test. 


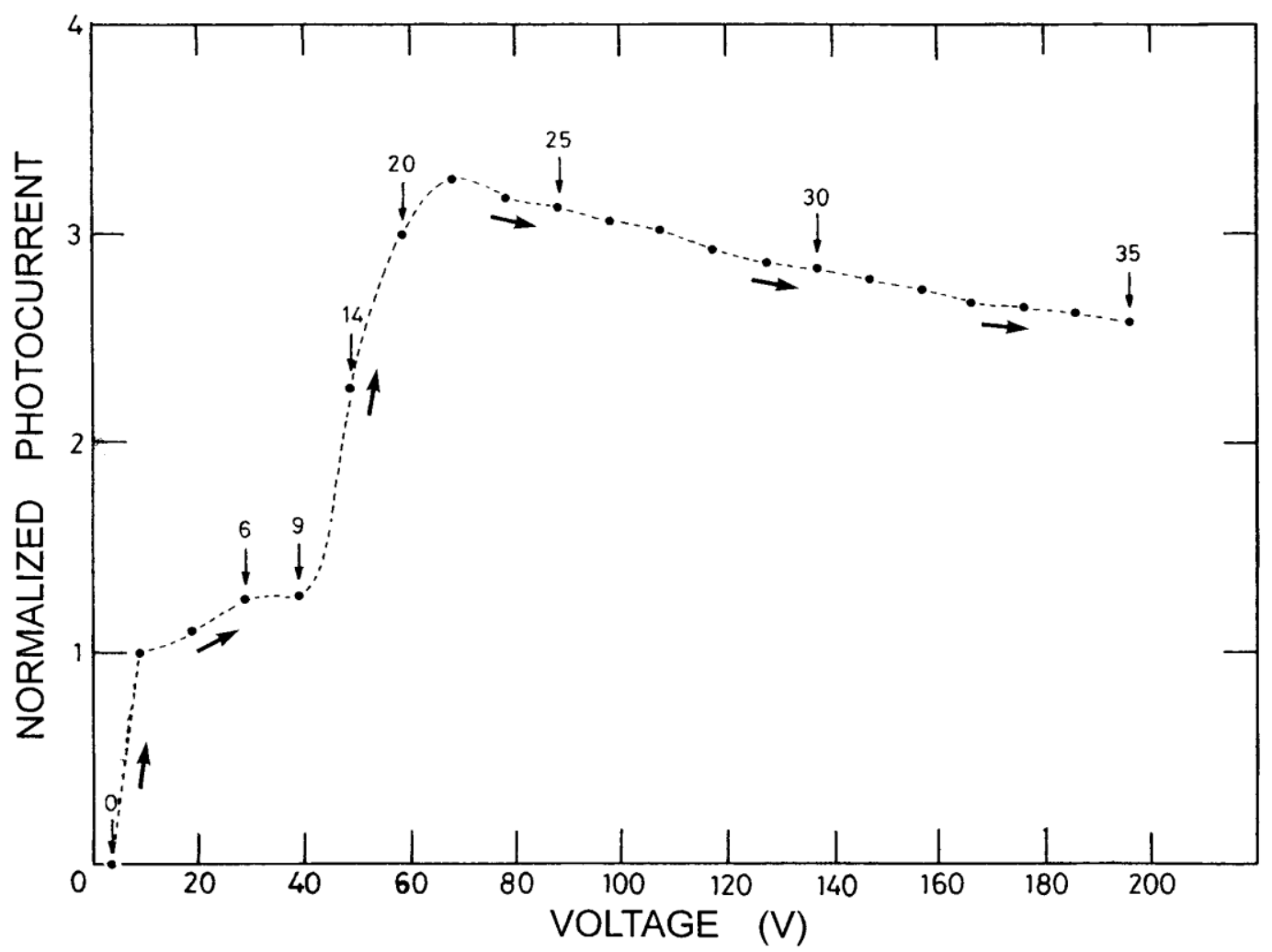

Fig. 4 Normalized photocurrent as a function of anode voltage below $196 \mathrm{~V}$, which was obtained at elapsed time of $82 \mathrm{~h}$ in the lifetime test in experiment II. Data were obtained by increasing the voltage from 9 to $196 \mathrm{~V}$ for $35 \mathrm{~min}$ in increments of about 10 $\mathrm{V}$. 


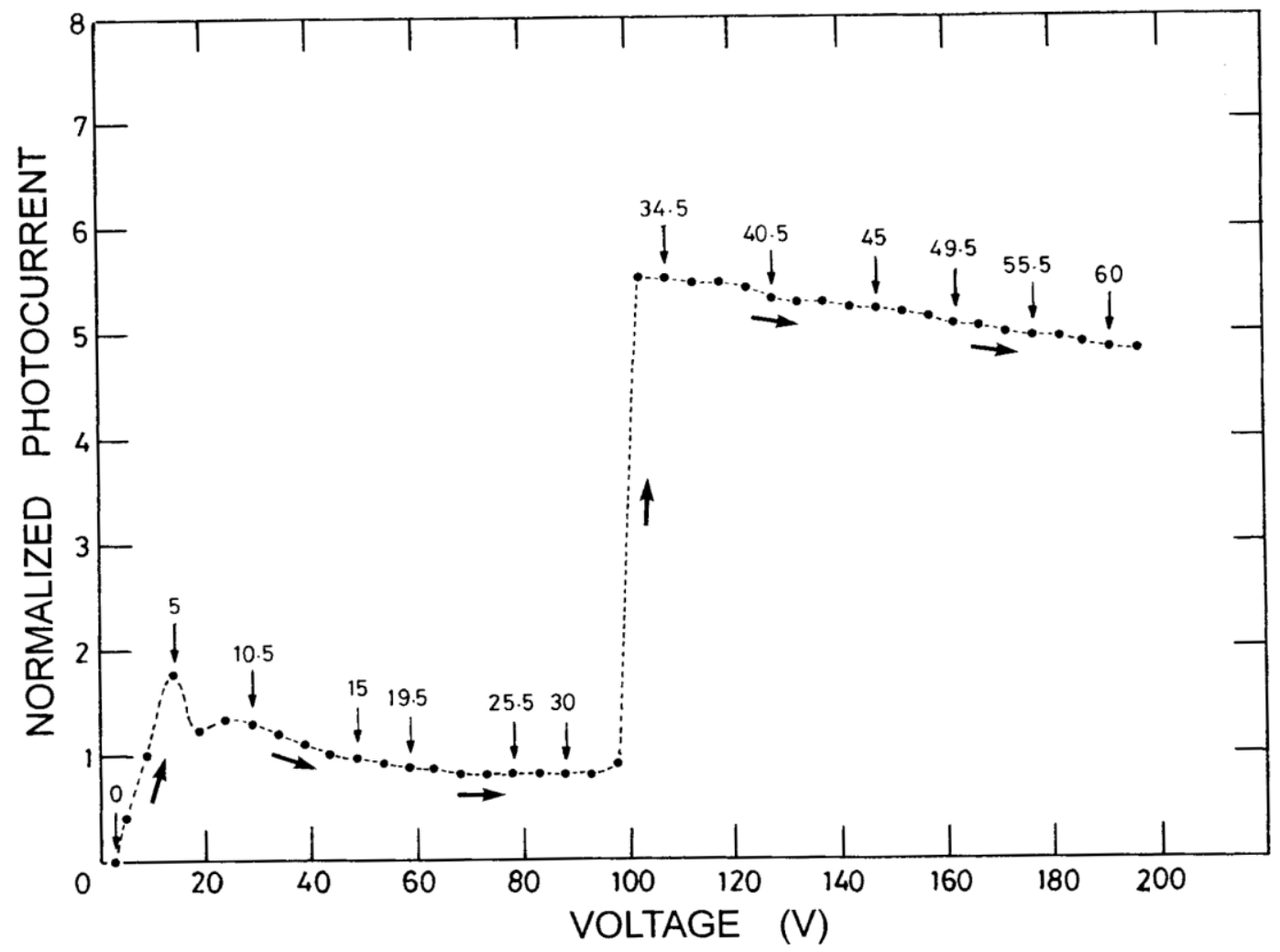

Fig. 5 Normalized photocurrent as a function of anode voltage below $196 \mathrm{~V}$, which was obtained at elapsed time of $175 \mathrm{~h}$ in the lifetime test in experiment II. Data were obtained by increasing the voltage very gradually from 3 to $196 \mathrm{~V}$ for $61.5 \mathrm{~min}$ in increments of approximately $5 \mathrm{~V}$. 


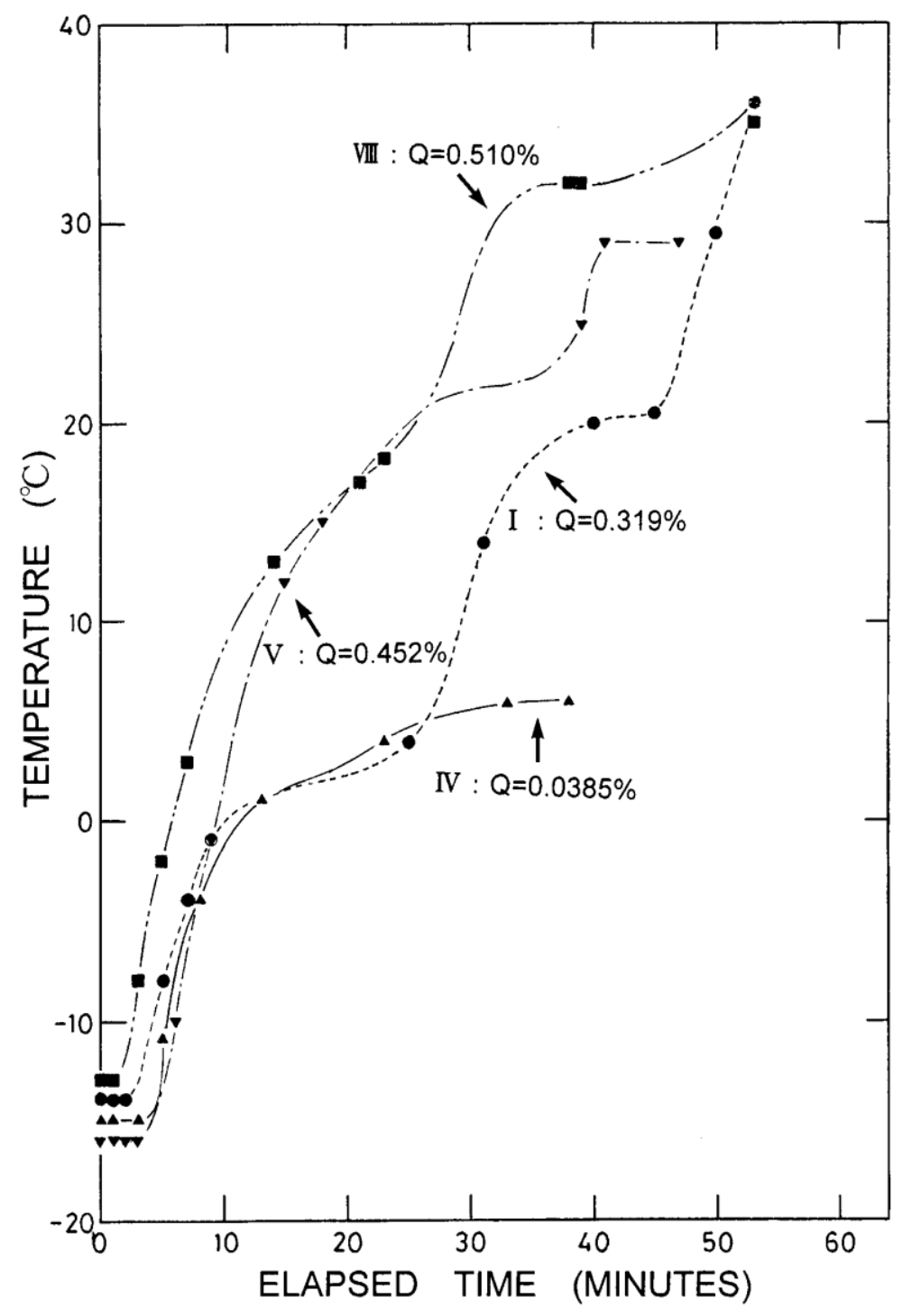

Fig. 6 Temperature of the cathode tip as a function of elapsed time (min) from the second $\mathrm{Sb}$ deposition to the first detection of photoelectrons in experiments I, IV, V, and VIII, where the first detected quantum efficiencies were initially smaller than $1 \%$. 


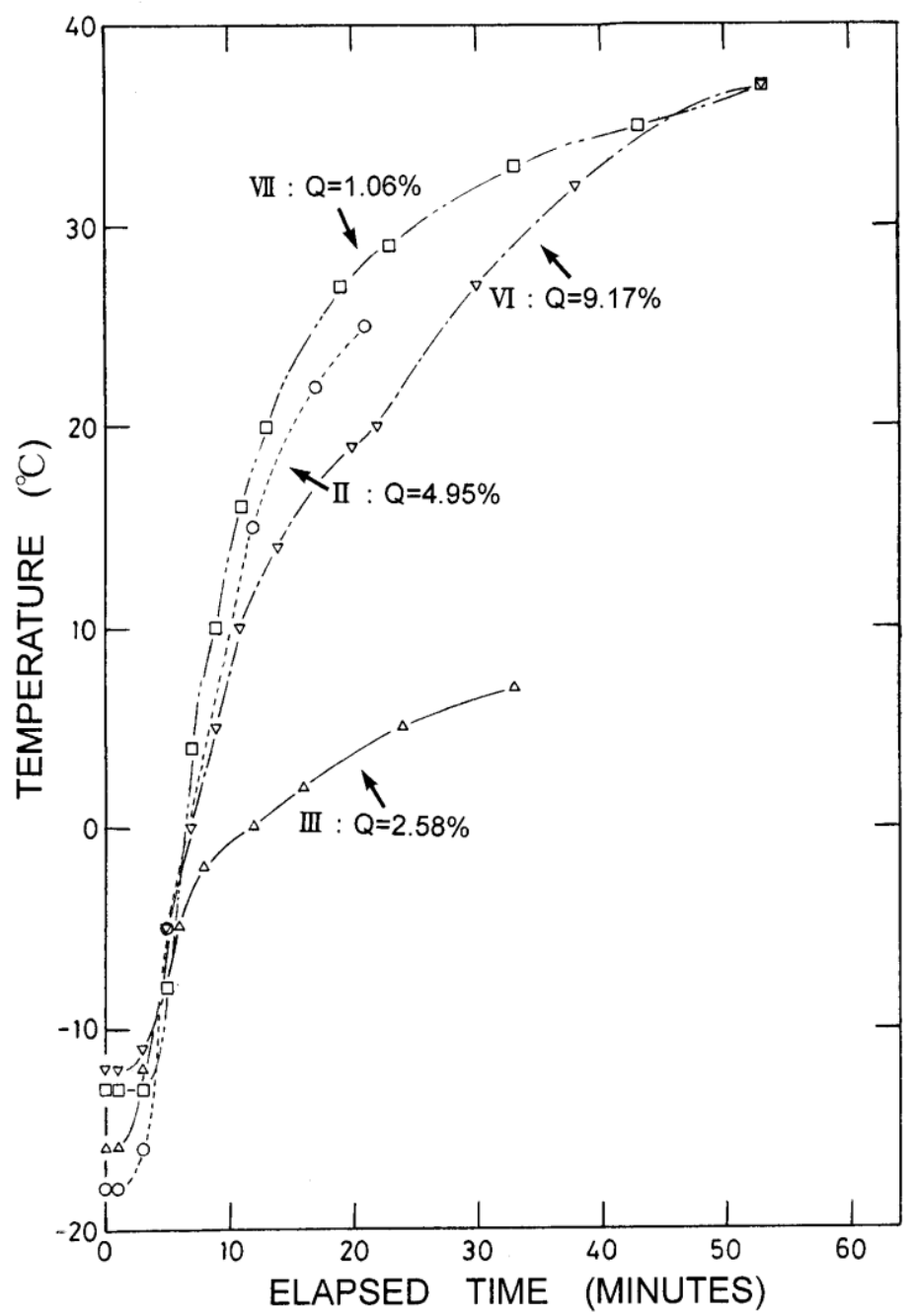

Fig. 7 Temperature of the cathode tip as a function of elapsed time (min) from the second $\mathrm{Sb}$ deposition to the first detection of photoelectrons for experiments II, III, VI, and VII, where the first detected quantum efficiencies were larger than $1 \%$. 


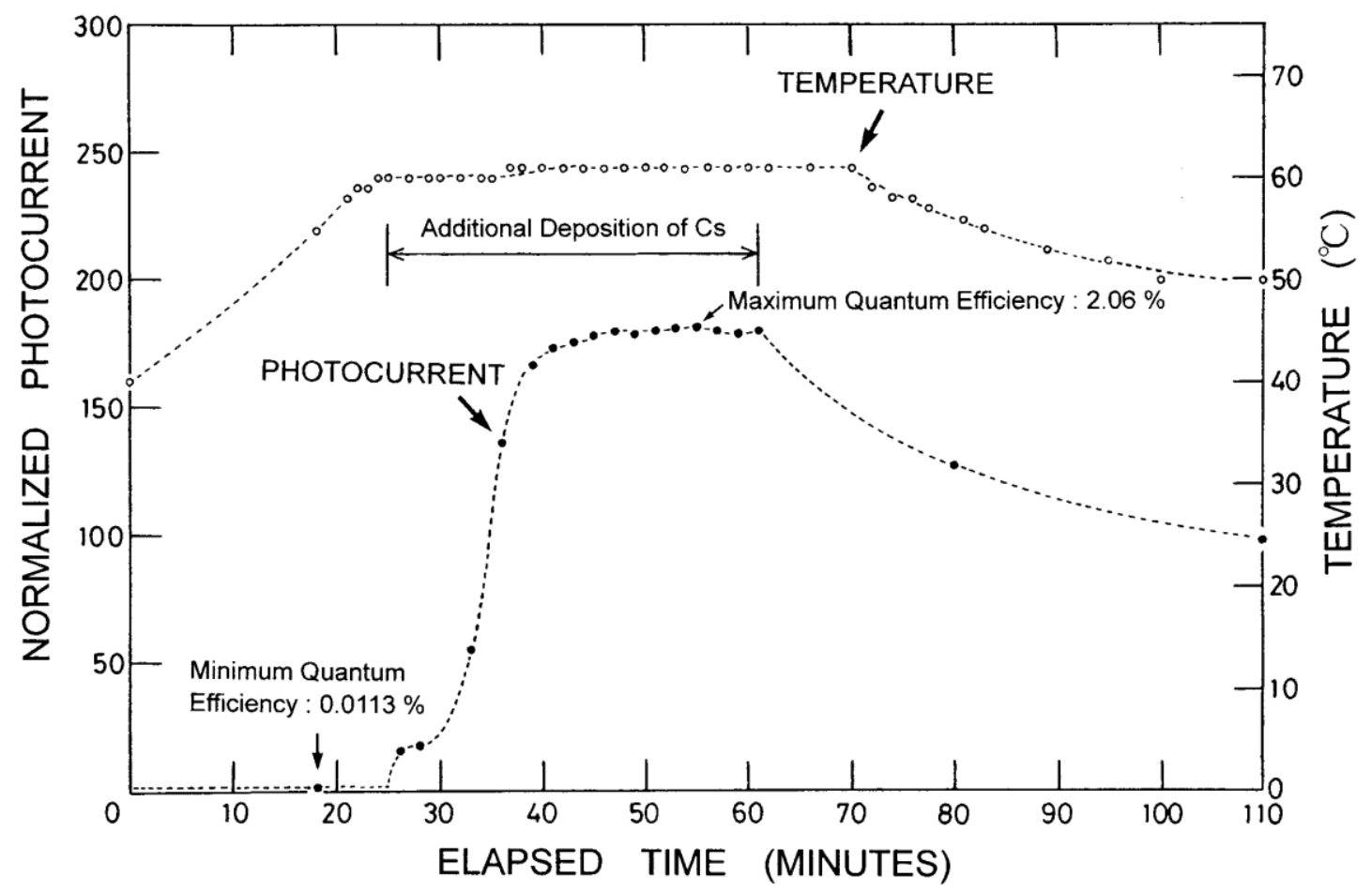

Fig. 8 Normalized photocurrent and cathode temperature as a function of elapsed time during additional $\mathrm{Cs}$ deposition in experiment $\mathrm{I}$. The time 0 min corresponds to the elapsed time of $46 \mathrm{~h}$ in the lifetime test, and the vacuum level during additional deposition of Cs was 1.6-2.5 $\times 10^{-7} \mathrm{~Pa}$. 


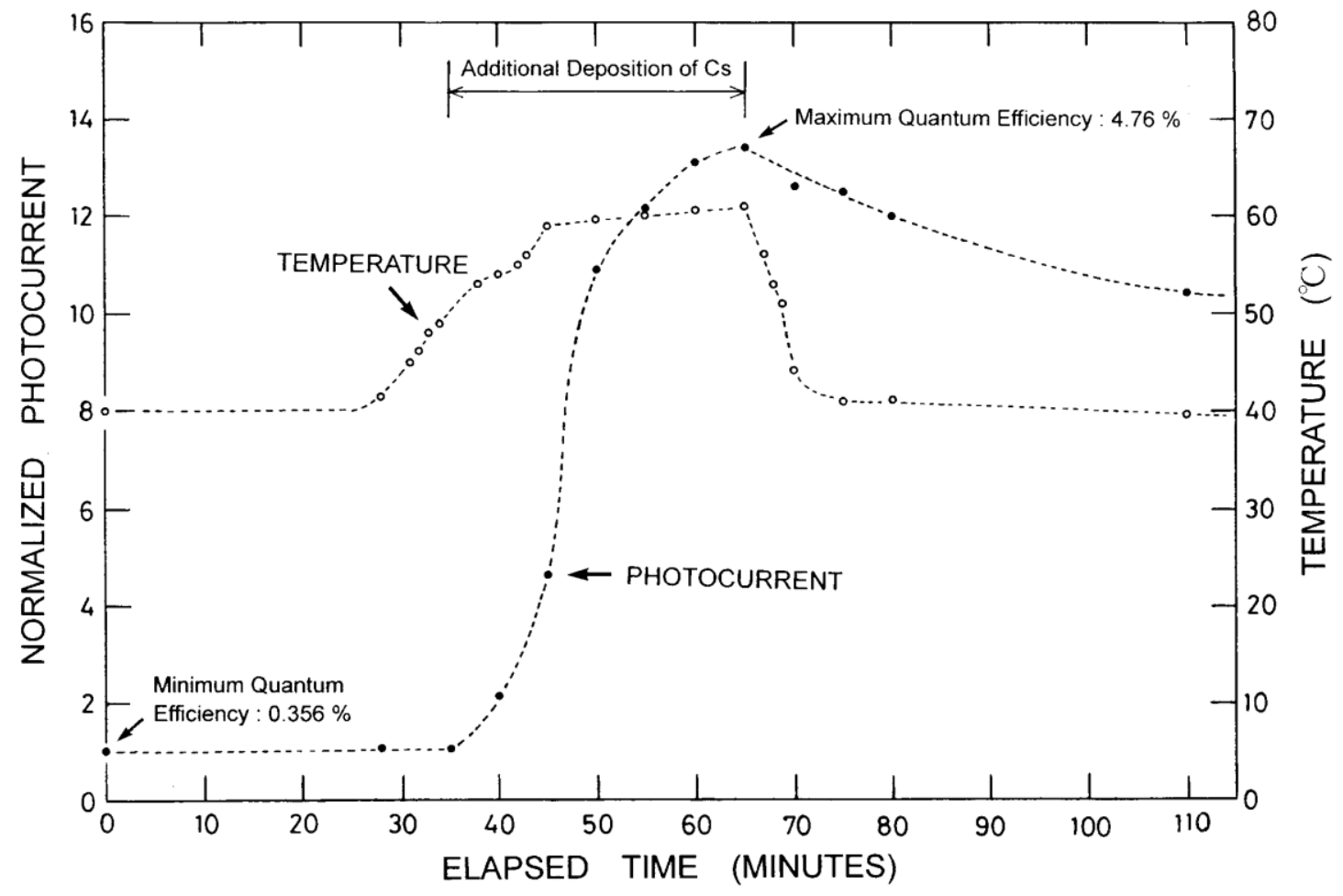

Fig. 9 Normalized photocurrent and cathode temperature as a function of elapsed time during additional $\mathrm{Cs}$ deposition in experiment $\mathrm{V}$. The time 0 min corresponds to 1 $\mathrm{h}$ before the lifetime test began, and the vacuum level during additional deposition of $\mathrm{Cs}$ was $1.6-2.0 \times 10^{-7} \mathrm{~Pa}$. 


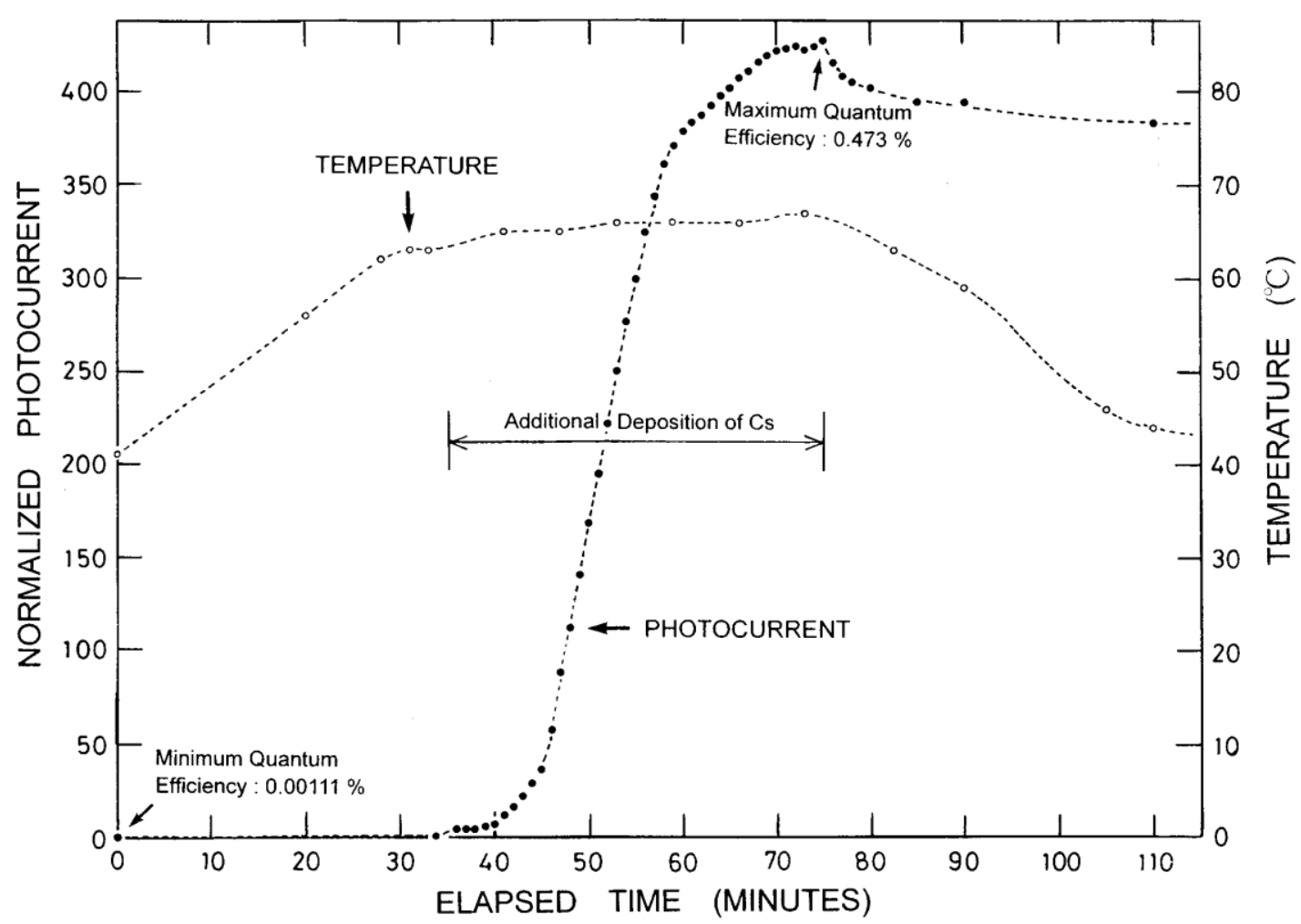

Fig. 10 Normalized photocurrent and cathode temperature as a function of elapsed time during additional Cs deposition in experiment VII. The time 0 min corresponds to the elapsed time of $23 \mathrm{~h}$ in the lifetime test, and the vacuum level during additional deposition of Cs was 1.0-1.1 $\times 10^{-7} \mathrm{~Pa}$. 


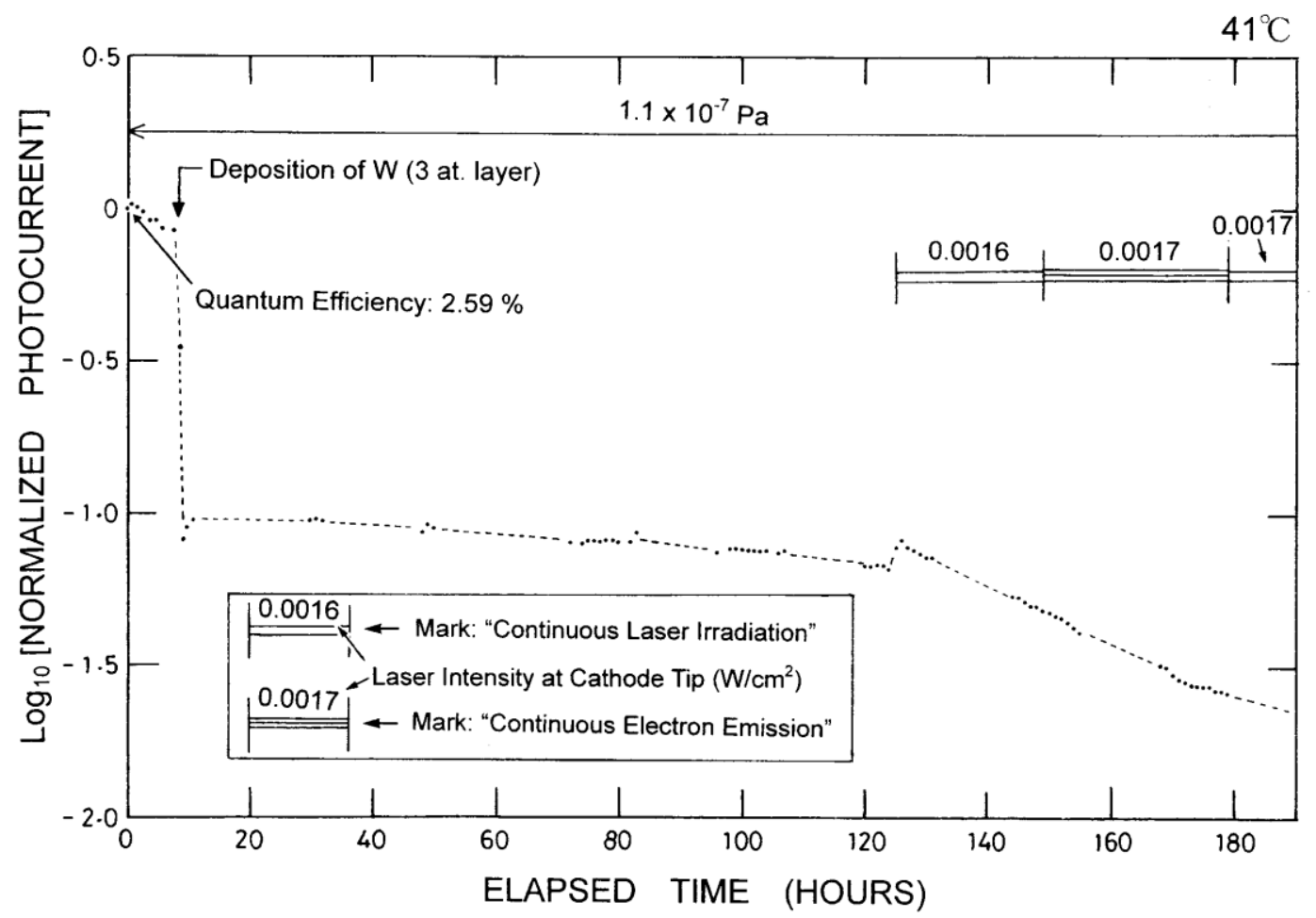

Fig. 11 Common logarithm of normalized photocurrent as a function of elapsed time from 0 to $190 \mathrm{~h}$ in lifetime test of $\mathrm{Cs}_{3} \mathrm{Sb}$ photocathode in experiment II. The intensity of the $405 \mathrm{~nm}$ laser at the cathode tip during continuous laser irradiation and continuous electron emission, the vacuum level, and the time of $\mathrm{W}$ deposition are shown. 


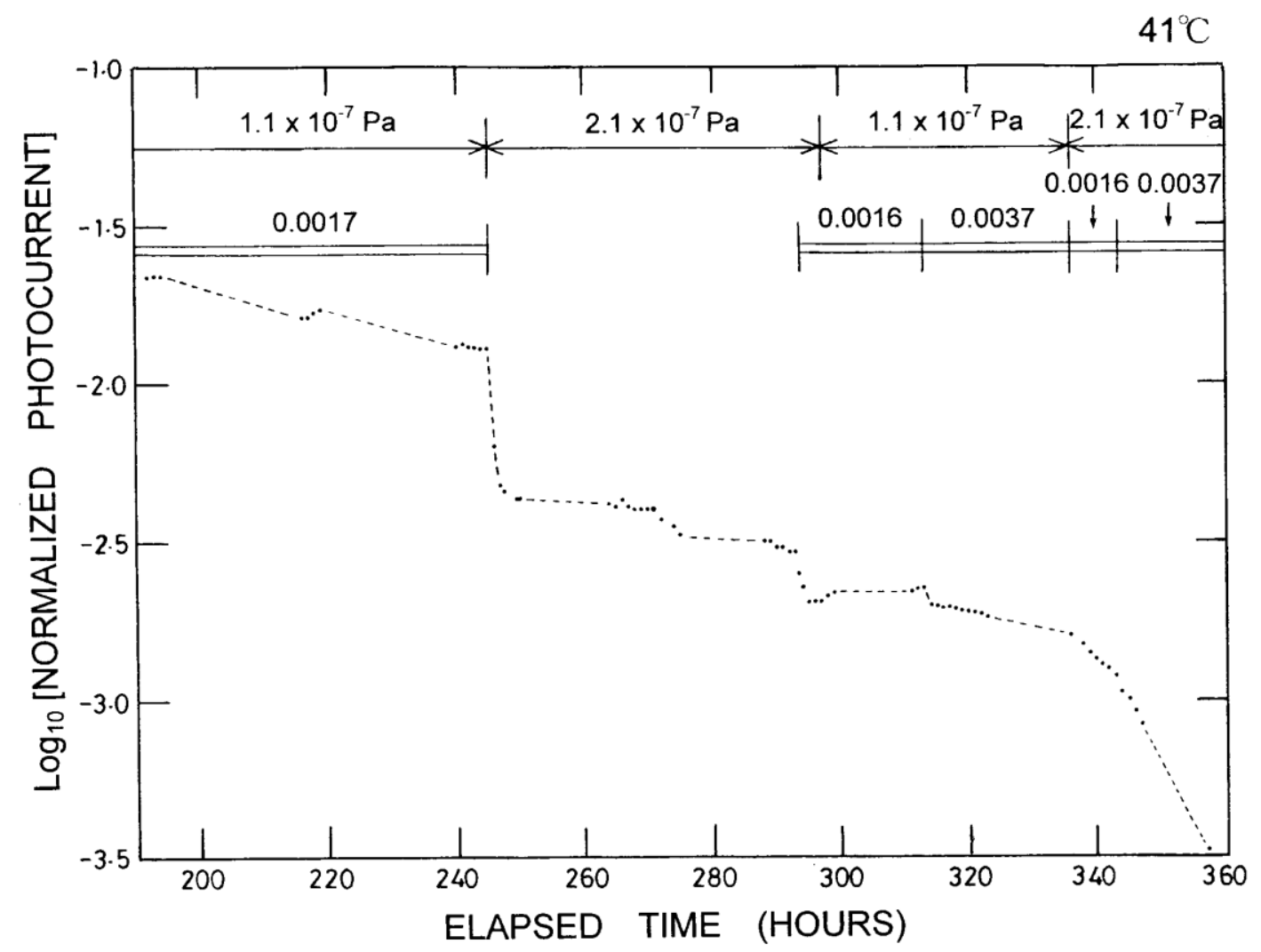

Fig. 12 Common logarithm of normalized photocurrent as a function of elapsed time from 190 to $347 \mathrm{~h}$ in lifetime test of $\mathrm{Cs}_{3} \mathrm{Sb}$ photocathode in experiment II. The intensity of the $405 \mathrm{~nm}$ laser at the cathode tip during continuous laser irradiation, and the vacuum level are shown. This figure continues Fig. 11. 


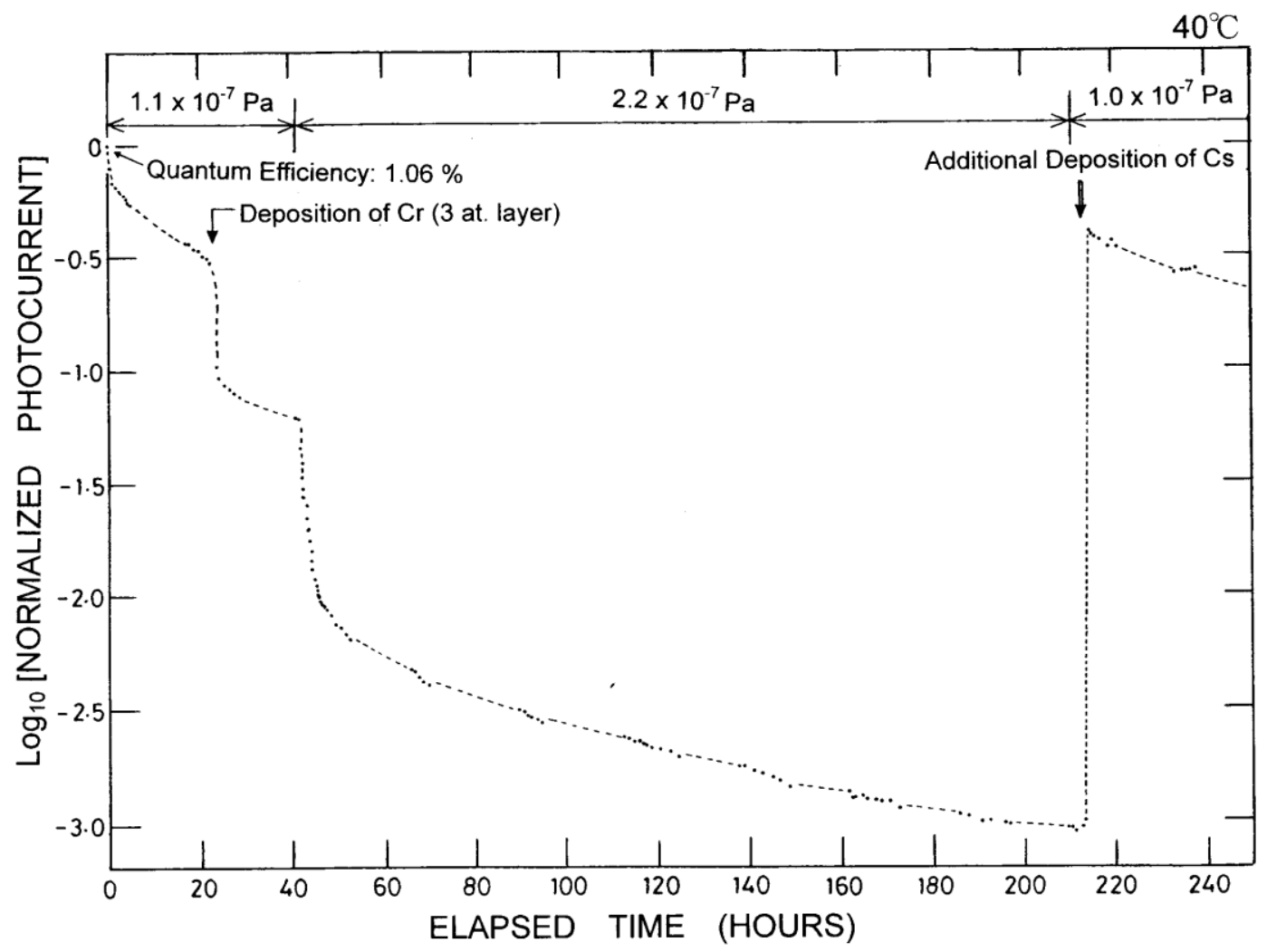

Fig. 13 Common logarithm of normalized photocurrent as a function of elapsed time from 0 to $250 \mathrm{~h}$ in lifetime test of $\mathrm{Cs}_{3} \mathrm{Sb}$ photocathode in experiment VII. The vacuum level, and the times of additional $\mathrm{Cs}$ deposition and $\mathrm{Cr}$ deposition are shown. 


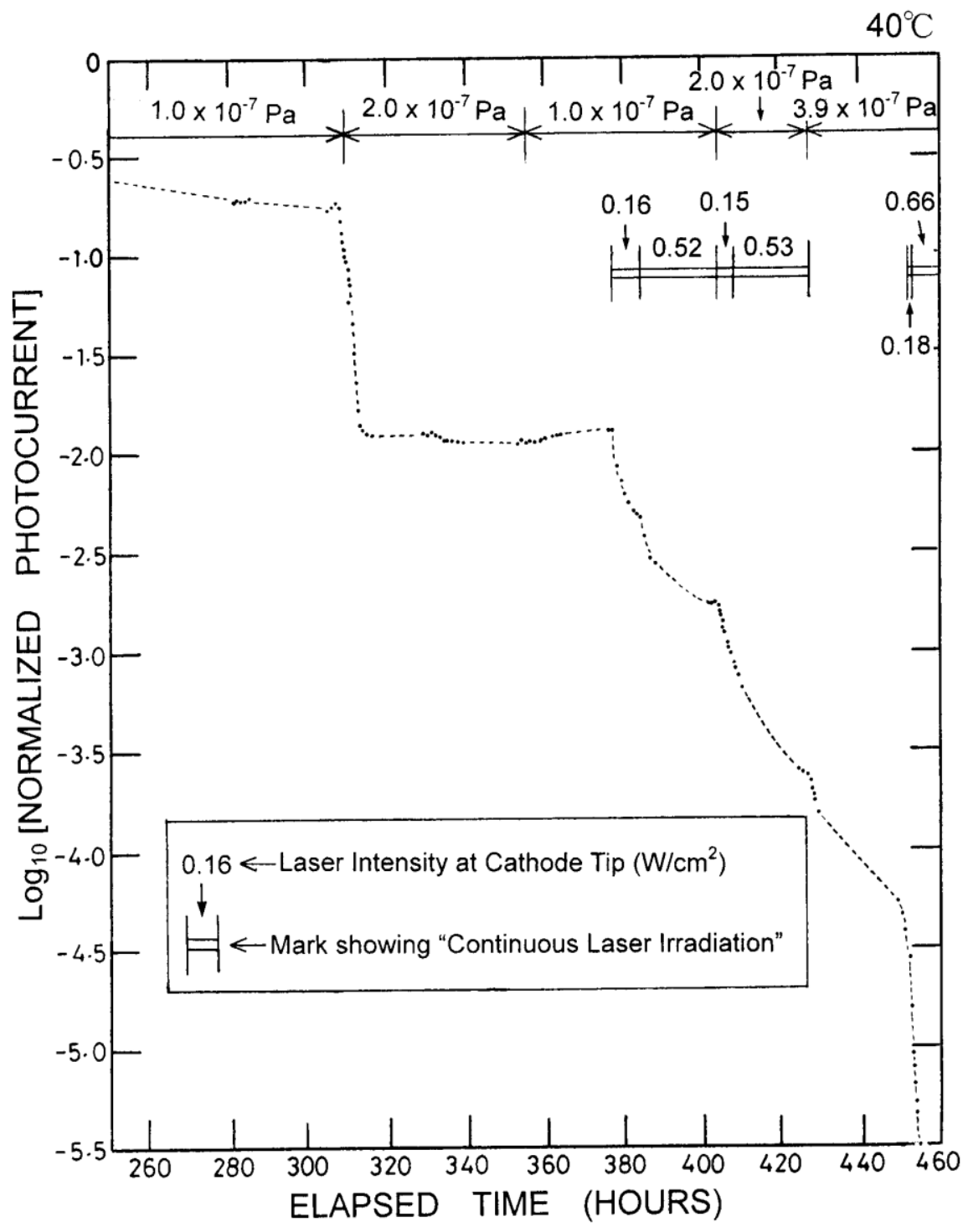

Fig. 14 Common logarithm of normalized photocurrent as a function of elapsed time from 250 to $455 \mathrm{~h}$ in lifetime test of $\mathrm{Cs}_{3} \mathrm{Sb}$ photocathode in experiment VII. The intensities of the 405-nm laser at the cathode tip during the continuous laser irradiation, and the vacuum level are also shown. This figure continues Fig. 13. 